\title{
Dynamical Behavior of the Stochastic Delay Mutualism System
}

\author{
Peiyan Xia, ${ }^{1,2}$ Daqing Jiang, ${ }^{1,3}$ and Xiaoyue $\mathrm{Li}^{1}$ \\ ${ }^{1}$ School of Mathematics and Statistics, Northeast Normal University, Changchun, Jilin 130024, China \\ ${ }^{2}$ School of College of Basic Sciences, Changchun University of Technology, Changchun, Jilin 130021, China \\ ${ }^{3}$ College of Sciences, China University of Petroleum, Qingdao 266580, China
}

Correspondence should be addressed to Daqing Jiang; daqingjiang2010@hotmail.com

Received 11 February 2014; Accepted 9 April 2014; Published 29 May 2014

Academic Editor: Juntao Sun

Copyright (C) 2014 Peiyan Xia et al. This is an open access article distributed under the Creative Commons Attribution License, which permits unrestricted use, distribution, and reproduction in any medium, provided the original work is properly cited.

We discuss the dynamical behavior of the stochastic delay three-specie mutualism system. We develop the technique for stochastic differential equations to deal with the asymptotic property. Using it we obtain the existence of the unique positive solution, the asymptotic properties, and the nonpersistence. Finally, we give the numerical examinations to illustrate our results.

\section{Introduction}

The classical Lotka-Volterra model for two mutualistic species is described by the ordinary differential equation (ODE)

$$
\begin{aligned}
& \dot{x}_{1}(t)=x_{1}(t)\left[r_{1}-a_{11} x_{1}(t)+a_{12} x_{2}(t)\right], \\
& \dot{x}_{2}(t)=x_{2}(t)\left[r_{2}+a_{21} x_{1}(t)-a_{22} x_{2}(t)\right] .
\end{aligned}
$$

There are many extensive literatures concerned with the dynamics of this model and we do not mention them here except [1]. Goh [1] showed that if $a_{11} a_{22}>a_{12} a_{21}$ holds, system (1) has a stable and globally attractive equilibrium point $x^{*}=\left(x_{1}^{*}, x_{2}^{*}\right)$ with the following property:

$$
x_{1}(t) \longrightarrow x_{1}^{*}, \quad x_{2}(t) \longrightarrow x_{2}^{*}, \quad \text { as } t \longrightarrow \infty,
$$

where

$$
x_{1}^{*}=\frac{r_{1} a_{22}+r_{2} a_{12}}{a_{11} a_{22}-a_{12} a_{21}}>0, \quad x_{2}^{*}=\frac{r_{2} a_{11}+r_{1} a_{21}}{a_{11} a_{22}-a_{12} a_{21}}>0 .
$$

In fact, in many physical as well as biological systems, many studies indicate that time delay widely exists in nature, for examples, in [2-7]. When the growth rate of each specie is affected by the time delay, as a result, (1) becomes a delay differential equation (DDE)

$$
\begin{aligned}
& \dot{x}_{1}(t)=x_{1}(t)\left[r_{1}-a_{11} x_{1}(t-\tau)+a_{12} x_{2}(t-\tau)\right], \\
& \dot{x}_{2}(t)=x_{2}(t)\left[r_{2}+a_{21} x_{1}(t-\tau)-a_{22} x_{2}(t-\tau)\right] .
\end{aligned}
$$

In [4], He and Gopalsamy obtained a supercritical Hopfbifurcation of (4) at $\tau=\tau^{*}$ (a constant) and proved that the equilibrium $\left(x_{1}^{*}, x_{2}^{*}\right)$ is no longer asymptotically stable as the delay increases to $\tau^{*}$. If only the interspecific positive feedback terms are affected by the delay, (1) becomes

$$
\begin{aligned}
& \dot{x}_{1}(t)=x_{1}(t)\left[r_{1}-a_{11} x_{1}(t)+a_{12} x_{2}(t-\tau)\right], \\
& \dot{x}_{2}(t)=x_{2}(t)\left[r_{2}+a_{21} x_{1}(t-\tau)-a_{22} x_{2}(t)\right] .
\end{aligned}
$$

The positive equilibrium $\left(x_{1}^{*}, x_{2}^{*}\right)$ of (5) is globally attractive if $a_{11} a_{22}>a_{12} a_{21}$ holds, awhich implies the delay is harmless.

Population systems are often subject to environmental noise and many authors have investigated the dynamical behaviors of stochastic population systems, for examples, in [8-26]. May [27] revealed that the parameters of the stochastic systems always fluctuate around their average values and the solution also fluctuates around its average value. If we still use $r_{i}$ to denote the average growth rate, then the intrinsic growth rate becomes

$$
r_{i} \longrightarrow r_{i}+\sigma_{i} \dot{B}_{i}(t)
$$

where $\dot{B}_{i}(t)$ is white noise and $\sigma_{i}$ is a positive constant representing the intensity of the noise. As a result, 
the mutualism system (1) becomes a stochastic differential equation (SDE)

$$
\begin{aligned}
& \dot{x}_{1}(t)=x_{1}(t)\left[\left(r_{1}-a_{11} x_{1}(t)+a_{12} x_{2}(t)\right) d t+\sigma_{1} d B_{1}(t)\right] \\
& \dot{x}_{2}(t)=x_{2}(t)\left[\left(r_{2}+a_{21} x_{1}(t)-a_{22} x_{2}(t)\right) d t+\sigma_{2} d B_{2}(t)\right] .
\end{aligned}
$$

Ji et al. in [14] analyzed the long-time asymptotic behavior of the system (7) and obtained the ergodic property and its stationary distribution.

Let us take a further step by considering a 3-dimensional mutualism system

$$
\begin{aligned}
& \dot{x}_{1}(t)=x_{1}(t)\left[r_{1}-a_{11} x_{1}(t)+a_{12} x_{2}(t-\tau)+a_{13} x_{3}(t-\tau)\right], \\
& \dot{x}_{2}(t)=x_{2}(t)\left[r_{2}+a_{21} x_{1}(t-\tau)-a_{22} x_{2}(t)+a_{23} x_{3}(t-\tau)\right], \\
& \dot{x}_{3}(t)=x_{3}(t)\left[r_{3}+a_{31} x_{1}(t-\tau)+a_{32} x_{2}(t-\tau)-a_{33} x_{3}(t)\right],
\end{aligned}
$$

subject to the white noise. As a result, it becomes a stochastic delay differential equation (SDDE)

$$
\begin{aligned}
d x_{1}(t)=x_{1}(t)[ & \left(r_{1}-a_{11} x_{1}(t)+a_{12} x_{2}(t-\tau)\right. \\
& \left.\left.+a_{13} x_{3}(t-\tau)\right) d t+\sigma_{1} d B_{1}(t)\right], \\
d x_{2}(t)=x_{2}(t)[ & \left(r_{2}+a_{21} x_{1}(t-\tau)-a_{22} x_{2}(t)\right. \\
& \left.\left.+a_{23} x_{3}(t-\tau)\right) d t+\sigma_{2} d B_{2}(t)\right], \\
d x_{3}(t)=x_{3}(t)[ & \left(r_{3}+a_{31} x_{1}(t-\tau)+a_{32} x_{2}(t-\tau)\right. \\
& \left.\left.-a_{33} x_{3}(t)\right) d t+\sigma_{2} d B_{2}(t)\right] .
\end{aligned}
$$

Our aim is to investigate the long-time asymptotic behavior of SDDE (9). This paper is organized as follows. In order to obtain better dynamic properties of SDDE (9), we show that there exists a unique global positive solution with any initial positive value under some assumptions in Section 2. Then, we estimate the expectation in time average of the distance between the solution of (9) and the positive equilibrium point of the deterministic model (8); namely,

$$
\limsup _{t \rightarrow \infty} \frac{1}{t} \int_{0}^{t} E\left\|x(t)-x^{*}\right\| \leq K(\sigma)
$$

where $x^{*}$ is the unique positive equilibrium point of system (8). In Section 3, we prove that system (9) is persistent in time average as the intensity of the white noise is small and yields the limit of the solution in time average. In Section 4, we obtain the nonpersistence of system (9) as the intensity of noise is big. Finally, in Section 5, we illustrate our results by some numerical examinations.

Throughout this paper, unless otherwise specified, let $\left(\Omega,\left\{\mathscr{F}_{t}\right\}_{t>0}, P\right)$ denote a complete probability space with a filtration $\left\{\mathscr{F}_{t}\right\}_{t \geq 0}$ satisfying the usual conditions (i.e., it is right continuous and $\mathscr{F}_{0}$ contains all $P$-null sets). Denote by $R_{+}^{3}$ the positive cone in $R^{3}$; namely, $R_{+}^{3}=\left\{x=\left(x_{1}, x_{2}, x_{3}\right)^{T} \in R^{3}\right.$ : $\left.x_{i}>0, i=1,2,3\right\}$. Let $\tau>0$ and denote by $C\left([-\tau, 0] ; R_{+}^{3}\right)$ the family of the continuous functions from $[-\tau, 0]$ to $R_{+}^{3}$. For $x \in R^{3}$, its norm is denoted by $|x|=\left|x_{1}\right|+\left|x_{2}\right|+\left|x_{3}\right|$.

To discuss the dynamical behavior of (9), we impose the following assumption.

Assumption 1. Consider $a_{i j}>0, i, j=1,2,3$ and $a_{11}>a_{12}+$ $a_{13}, a_{22}>a_{21}+a_{23}, a_{33}>a_{31}+a_{32}$.

Assumption 2. Consider $r_{i}>\sigma_{i}^{2} / 2, i=1,2,3$.

\section{Existence and Uniqueness of the Positive Solution}

In population dynamics, the existence of the global positive solution is necessary. In order for a SDE to have a unique global (i.e., no explosion at any finite time) solution for any given initial value, its coefficients are generally required to satisfy the linear growth condition and local Lipschitz condition (Arnold et al. [28], Mao [23]). However, the coefficients of system (9) do not satisfy the linear growth condition, though they are locally Lipschitz continuous, so the solution of system (9) may explode at a finite time. So we prepare the following useful lemma and then yield the existence of the positive solution by using it.

Lemma 3. Under Assumption 1, then we have

(1) $a_{22} a_{33}-a_{23} a_{32}>0, \quad a_{11} a_{33}-a_{13} a_{31}>0$,

$a_{11} a_{22}-a_{12} a_{21}>0$,

(2) $\left(a_{22} a_{33}-a_{23} a_{32}\right)+\left(a_{33} a_{21}+a_{31} a_{23}\right)+\left(a_{32} a_{21}+a_{31} a_{22}\right)$

$>0$,

(3) $\left(a_{11} a_{33}-a_{13} a_{31}\right)+\left(a_{33} a_{12}+a_{32} a_{13}\right)+\left(a_{11} a_{32}+a_{31} a_{12}\right)$

$>0$,

(4) $\left(a_{11} a_{22}-a_{12} a_{21}\right)+\left(a_{12} a_{23}+a_{22} a_{13}\right)+\left(a_{11} a_{23}+a_{21} a_{13}\right)$

$>0$,

(5) $\left|\begin{array}{ccc}-a_{11} & a_{12} & a_{13} \\ a_{21} & -a_{22} & a_{23} \\ a_{31} & a_{32} & -a_{33}\end{array}\right|=-a_{11} a_{22} a_{33}+a_{11} a_{23} a_{32}+a_{22} a_{13} a_{31}$

$$
+a_{33} a_{12} a_{21}+a_{12} a_{23} a_{31}+a_{21} a_{32} a_{13}
$$

$<0$.

Proof. The assertions (1)-(5) are obviously obtained from $a_{11}>a_{12}+a_{13}, a_{22}>a_{21}+a_{23}, a_{33}>a_{31}+a_{32}$, and $a_{i j}>0, i, j=1,2,3$. Here we omit the proof.

Theorem 4. Under Assumption 1, for any given initial value $x(\cdot) \in C\left([-\tau, 0] ; R_{+}^{3}\right)$, there is a unique positive solution $x(t)$ to system (9) on $t \geq-\tau$ and the solution will remain in $R_{+}^{3}$ with probability 1; namely, $x(t) \in R_{+}^{3}$ for all $t \geq-\tau$ a. $s$. 
Proof. Firstly, define a $C^{2}$ function $V_{1}: R_{+}^{3} \rightarrow R_{+}$by

$$
\begin{aligned}
& V_{1}\left(x_{1}, x_{2}, x_{3}\right) \\
& =c_{1}\left[x_{1}(t)-1-\log x_{1}(t)\right]+c_{2}\left[x_{2}(t)-1-\log x_{2}(t)\right] \\
& \quad+c_{3}\left[x_{3}(t)-1-\log x_{3}(t)\right]
\end{aligned}
$$

where

$$
\begin{aligned}
c_{1}= & \left(\left(a_{22} a_{33}-a_{23} a_{32}\right)+\left(a_{33} a_{21}+a_{31} a_{23}\right)\right. \\
& \left.+\left(a_{32} a_{21}+a_{31} a_{22}\right)\right) \\
\times & \left(a_{11} a_{22} a_{33}-a_{11} a_{23} a_{32}-a_{22} a_{13} a_{31}\right. \\
& \left.-a_{33} a_{12} a_{21}-a_{12} a_{23} a_{31}-a_{21} a_{32} a_{13}\right)^{-1}, \\
c_{2}= & \left(\left(a_{11} a_{33}-a_{13} a_{31}\right)+\left(a_{33} a_{12}+a_{32} a_{13}\right)\right. \\
& \left.+\left(a_{11} a_{32}+a_{31} a_{12}\right)\right) \\
\times & \left(a_{11} a_{22} a_{33}-a_{11} a_{23} a_{32}-a_{22} a_{13} a_{31}\right. \\
& \left.\quad-a_{33} a_{12} a_{21}-a_{12} a_{23} a_{31}-a_{21} a_{32} a_{13}\right)^{-1}, \\
c_{3}= & \left(\left(a_{11} a_{22}-a_{12} a_{21}\right)+\left(a_{12} a_{23}+a_{22} a_{13}\right)\right. \\
& \left.+\left(a_{11} a_{23}+a_{21} a_{13}\right)\right) \\
\times & \left(a_{11} a_{22} a_{33}-a_{11} a_{23} a_{32}-a_{22} a_{13} a_{31}\right. \\
& \left.\quad-a_{33} a_{12} a_{21}-a_{12} a_{23} a_{31}-a_{21} a_{32} a_{13}\right)^{-1} .
\end{aligned}
$$

From Lemma 3, $c_{i}>0, i=1,2,3$. So, $V_{1}\left(x_{1}, x_{2}, x_{3}\right)$ is nonnegative. By Itô's formula, we obtain

$$
\begin{aligned}
d V_{1}\left(x_{1}, x_{2}, x_{3}\right)= & L V_{1}\left(x_{1}, x_{2}, x_{3}\right) d t \\
& +\sum_{i=1}^{3} c_{i}\left[x_{i}(t)-1\right] \sigma_{i} d B_{i}(t),
\end{aligned}
$$

where

$$
\begin{aligned}
& L V_{1}\left(x_{1}, x_{2}, x_{3}\right) \\
& =c_{1}\left[x_{1}(t)-1\right]\left[r_{1}-a_{11} x_{1}(t)\right. \\
& \left.+a_{12} x_{2}(t-\tau)+a_{13} x_{3}(t-\tau)\right] \\
& +c_{2}\left[x_{2}(t)-1\right]\left[r_{2}+a_{21} x_{1}(t-\tau)-a_{22} x_{2}(t)\right. \\
& \left.+a_{23} x_{3}(t-\tau)\right] \\
& +c_{3}\left[x_{3}(t)-1\right]\left[r_{3}+a_{31} x_{1}(t-\tau)\right.
\end{aligned}
$$$$
\left.+a_{32} x_{2}(t-\tau)-a_{33} x_{3}(t)\right]
$$$$
+\frac{c_{1} \sigma_{1}^{2}+c_{2} \sigma_{2}^{2}+c_{3} \sigma_{3}^{2}}{2}
$$

By Young's inequality, we have

$$
\begin{aligned}
& L V_{1}\left(x_{1}, x_{2}, x_{3}\right) \\
& =c_{1}\left[\left(r_{1}+a_{11}\right) x_{1}(t)-a_{12} x_{2}(t-\tau)\right. \\
& -a_{13} x_{3}(t-\tau)-a_{11} x_{1}^{2}(t)+a_{12} x_{1}(t) x_{2}(t-\tau) \\
& \left.+a_{13} x_{1}(t) x_{3}(t-\tau)-r_{1}+\frac{\sigma_{1}^{2}}{2}\right] \\
& +c_{2}\left[\left(r_{2}+a_{22}\right) x_{2}(t)-a_{21} x_{1}(t-\tau)\right. \\
& -a_{23} x_{3}(t-\tau)-a_{22} x_{2}^{2}(t)+a_{21} x_{2}(t) x_{1}(t-\tau) \\
& \left.+a_{23} x_{2}(t) x_{3}(t-\tau)-r_{2}+\frac{\sigma_{2}^{2}}{2}\right] \\
& +c_{3}\left[\left(r_{3}+a_{33}\right) x_{3}(t)-a_{31} x_{1}(t-\tau)\right. \\
& -a_{32} x_{2}(t-\tau)-a_{33} x_{3}^{2}(t)+a_{31} x_{3}(t) x_{1}(t-\tau) \\
& \left.+a_{32} x_{3}(t) x_{2}(t-\tau)-r_{3}+\frac{\sigma_{3}^{2}}{2}\right] \\
& \leq c_{1}\left[\left(r_{1}+a_{11}\right) x_{1}(t)-a_{12} x_{2}(t-\tau)\right. \\
& -a_{13} x_{3}(t-\tau)+\left(-a_{11}+\frac{a_{12}}{2}+\frac{a_{13}}{2}\right) x_{1}^{2}(t) \\
& \left.+\frac{a_{12}}{2} x_{2}^{2}(t-\tau)+\frac{a_{13}}{2} x_{3}^{2}(t-\tau)-r_{1}+\frac{\sigma_{1}^{2}}{2}\right] \\
& +c_{2}\left[\left(r_{2}+a_{22}\right) x_{2}(t)-a_{21} x_{1}(t-\tau)-a_{23} x_{3}(t-\tau)\right. \\
& +\left(-a_{22}+\frac{a_{21}}{2}+\frac{a_{23}}{2}\right) x_{2}^{2}(t) \\
& \left.+\frac{a_{21}}{2} x_{1}^{2}(t-\tau)+\frac{a_{23}}{2} x_{3}^{2}(t-\tau)-r_{2}+\frac{\sigma_{2}^{2}}{2}\right] \\
& +c_{3}\left[\left(r_{3}+a_{33}\right) x_{3}(t)-a_{31} x_{1}(t-\tau)\right. \\
& -a_{32} x_{2}(t-\tau)+\left(-a_{33}+\frac{a_{31}}{2}+\frac{a_{32}}{2}\right) x_{3}^{2}(t) \\
& \left.+\frac{a_{31}}{2} x_{1}^{2}(t-\tau)+\frac{a_{32}}{2} x_{2}^{2}(t-\tau)-r_{3}+\frac{\sigma_{3}^{2}}{2}\right] \text {. }
\end{aligned}
$$


Secondly, define

$$
\begin{aligned}
& V_{2}\left(x_{1}, x_{2}, x_{3}\right)=\int_{t}^{t+\tau} {\left[\left(\frac{a_{12} c_{1}}{2}+\frac{a_{32} c_{3}}{2}\right) x_{2}^{2}(s-\tau)\right.} \\
&+\left(\frac{a_{13} c_{1}}{2}+\frac{a_{23} c_{2}}{2}\right) x_{3}^{2}(s-\tau) \\
&\left.+\left(\frac{a_{21} c_{2}}{2}+\frac{a_{31} c_{3}}{2}\right) x_{1}^{2}(s-\tau)\right] d s .
\end{aligned}
$$

By Itô's formula, we have

$$
\begin{aligned}
d V_{2}( & \left.x_{1}, x_{2}, x_{3}\right) \\
= & {\left[\left(\frac{a_{12} c_{1}}{2}+\frac{a_{32} c_{3}}{2}\right) x_{2}^{2}(t)+\left(\frac{a_{13} c_{1}}{2}+\frac{a_{23} c_{2}}{2}\right) x_{3}^{2}(t)\right.} \\
& +\left(\frac{a_{21} c_{2}}{2}+\frac{a_{31} c_{3}}{2}\right) x_{1}^{2}(t)-\left(\frac{a_{12} c_{1}}{2}+\frac{a_{32} c_{3}}{2}\right) x_{2}^{2}(t-\tau) \\
& -\left(\frac{a_{13} c_{1}}{2}+\frac{a_{23} c_{2}}{2}\right) x_{3}^{2}(t-\tau) \\
& \left.-\left(\frac{a_{21} c_{2}}{2}+\frac{a_{31} c_{3}}{2}\right) x_{1}^{2}(t-\tau)\right] d t .
\end{aligned}
$$

Therefore, let

$$
V\left(x_{1}, x_{2}, x_{3}\right)=V_{1}\left(x_{1}, x_{2}, x_{3}\right)+V_{2}\left(x_{1}, x_{2}, x_{3}\right) .
$$

Equalities (16) and (18) imply that

$$
d V\left(x_{1}, x_{2}, x_{3}\right)=L V\left(x_{1}, x_{2}, x_{3}\right)+\sum_{i=1}^{3} c_{i}\left[x_{i}(t)-1\right] \sigma_{i} d B_{i}(t),
$$

where

$$
\begin{aligned}
& L V\left(x_{1}, x_{2}, x_{3}\right) \\
& \leq c_{1}\left[-x_{1}^{2}(t)\left(a_{11}-a_{12}-a_{13}\right)+\left(r_{1}+a_{11}\right) x_{1}(t)\right. \\
& \left.-a_{12} x_{2}(t-\tau)-a_{13} x_{3}(t-\tau)-r_{1}+\frac{\sigma_{1}^{2}}{2}\right] \\
& +c_{2}\left[-x_{2}^{2}(t)\left(a_{22}-a_{21}-a_{23}\right)+\left(r_{2}+a_{22}\right) x_{2}(t)\right. \\
& \left.-a_{21} x_{1}(t-\tau)-a_{23} x_{3}(t-\tau)-r_{2}+\frac{\sigma_{2}^{2}}{2}\right] \\
& +c_{3}\left[-x_{3}^{2}(t)\left(a_{33}-a_{31}-a_{32}\right)+\left(r_{3}+a_{33}\right) x_{3}(t)\right. \\
& \left.-a_{31} x_{1}(t-\tau)-a_{32} x_{2}(t-\tau)-r_{3}+\frac{\sigma_{3}^{2}}{2}\right] \leq K,
\end{aligned}
$$

where $K$ is a positive constant. By the method similar to that in [24], the proof is therefore completed.

Under Assumption 1, DDE (8) has a positive equilibrium $x^{*}=\left(x_{1}^{*}, x_{2}^{*}, x_{3}^{*}\right)$ which is globally attractive while the system with the stochastic perturbation has a unique global positive solution. It is natural to ask how to estimate the distance between the solution of the deterministic system and the solution of the stochastic system. The following theorem gives us an answer.

Theorem 5. Under Assumption 1, system (9) has the following property:

$$
\begin{aligned}
\limsup _{t \rightarrow \infty} \frac{1}{t} E \int_{0}^{t}\{ & \frac{\left(a_{11}-a_{12}-a_{13}\right) c_{1}+1}{2}\left[x_{1}(s)-x_{1}^{*}\right]^{2} \\
+ & \frac{\left(a_{22}-a_{21}-a_{23}\right) c_{2}+1}{2}\left[x_{2}(s)-x_{2}^{*}\right]^{2} \\
& \left.+\frac{\left(a_{33}-a_{31}-a_{32}\right) c_{3}+1}{2}\left[x_{3}(s)-x_{3}^{*}\right]^{2}\right\} d s \\
\leq & \frac{\sum_{i=1}^{3} c_{i} x_{i}^{*} \sigma_{i}^{2}}{2},
\end{aligned}
$$

where $x(t)$ is a solution on $t \geq \tau$ to (9) with an initial value $x(\cdot) \in C\left([-\tau, 0] ; R_{+}^{3}\right), c_{i}(i=1,2,3)$ is defined in the proof of Theorem 4 , and $x^{*}=\left(x_{1}^{*}, x_{2}^{*}, x_{3}^{*}\right)$ is the unique positive equilibrium of system (8); namely,

$$
\begin{aligned}
x_{1}^{*}= & \left(\left(a_{22} a_{33}-a_{23} a_{32}\right) r_{1}+\left(a_{12} a_{33}+a_{13} a_{32}\right) r_{2}\right. \\
& \left.+\left(a_{12} a_{23}+a_{13} a_{22}\right) r_{3}\right) \\
\times & \left(a_{11} a_{22} a_{33}-a_{11} a_{23} a_{32}-a_{22} a_{13} a_{31}\right. \\
& \left.\quad-a_{33} a_{12} a_{21}-a_{12} a_{23} a_{31}-a_{21} a_{32} a_{13}\right)^{-1}, \\
x_{2}^{*}= & \left(\left(a_{21} a_{33}+a_{23} a_{31}\right) r_{1}+\left(a_{11} a_{33}-a_{13} a_{31}\right) r_{2}\right. \\
& \left.+\left(a_{11} a_{23}+a_{13} a_{21}\right) r_{3}\right) \\
\times & \left(a_{11} a_{22} a_{33}-a_{11} a_{23} a_{32}-a_{22} a_{13} a_{31}\right. \\
& \left.\quad-a_{33} a_{12} a_{21}-a_{12} a_{23} a_{31}-a_{21} a_{32} a_{13}\right)^{-1}, \\
x_{3}^{*}=( & \left(a_{21} a_{32}+a_{22} a_{31}\right) r_{1}+\left(a_{11} a_{32}+a_{12} a_{31}\right) r_{2} \\
& \left.+\left(a_{11} a_{22}-a_{12} a_{21}\right) r_{3}\right) \\
\times & \left(a_{11} a_{22} a_{33}-a_{11} a_{23} a_{32}-a_{22} a_{13} a_{31}\right. \\
& \left.\quad-a_{33} a_{12} a_{21}-a_{12} a_{23} a_{31}-a_{21} a_{32} a_{13}\right)^{-1} .
\end{aligned}
$$

For brevity, we will give the proof in the appendix.

\section{Persistence in Time Average}

For convenience, we denote the unique global solution of system (9) by $x(t, \xi)$ with an initial data $\xi \in C\left([-\tau, 0] ; R_{3}^{+}\right)$. Theorem 4 shows that the solution of system (9) will remain positive under Assumption 1. This property gives us an opportunity to investigate how the solution varies in $R_{3}^{+}$. In 
population dynamics, one of the most attractive properties is persistence which means all species will coexist. Now we give the definition of persistence in time average.

Definition 6. System (9) is persistent in time average, if, for any initial data $\xi \in C\left([-\tau, 0] ; R_{+}^{3}\right)$, the solution $x(t, \xi)$ has the property that

$$
\begin{array}{r}
0<\liminf _{t \rightarrow \infty} \frac{1}{t} \int_{0}^{t} x_{i}(s) d s \leq \limsup _{t \rightarrow \infty} \frac{1}{t} \int_{0}^{t} x_{i}(s) d s<+\infty \\
\text { a.s. } i=1,2,3 .
\end{array}
$$

To prove that system (9) is persistent in time average, we will cite a lemma. Jiang and Shi in [17] discussed a stochastic nonautonomous logistic equation

$$
d N(t)=N(t)[(a(t)-b(t) N(t)) d t+\alpha(t) d B(t)]
$$

where $B(t)$ is 1-dimensional standard Brownian motion, $N(0)=N_{0}$, and $N_{0}$ is independent of $B(t)$. They obtained the following result.

Lemma 7 (see [17]). Assume that $a(t), b(t)$, and $\alpha(t)$ are bounded continuous functions defined on $[0, \infty), a(t)>0$, and $b(t)>0$. Then there exists a unique continuous positive solution of (25) for any initial value $N(0)=N_{0}>0$, which is global and represented by

$$
\begin{array}{r}
N(t)=\left(\exp \left\{\int_{0}^{t}\left[a(s)-\frac{\alpha^{2}(s)}{2}\right] d s+\alpha(s) d B(s)\right\}\right) \\
\times\left(\frac{1}{N_{0}}+\int_{0}^{t} b(s) \exp \left\{\int_{0}^{s}\left[a(\tau)-\frac{\alpha^{2}(\tau)}{2}\right] d \tau\right.\right. \\
+\alpha(\tau) d B(\tau)\} d s)^{-1}, \\
t \geq 0 .
\end{array}
$$

Moreover, the solution $N(t)$ has the property that

$$
\lim _{t \rightarrow \infty} \frac{\log N(t)}{t}=0, \quad \text { a.s. }
$$

Remark 8. Let $\phi_{i}(t), i=1,2,3$, be the solution of the following equation:

$$
\begin{array}{r}
d \phi_{i}(t)=\phi_{i}(t)\left[\left(r_{i}-a_{i i} \phi_{i}(t)\right) d t+\sigma_{i} d B_{i}(t)\right], \\
t \geq 0, \quad i=1,2,3,
\end{array}
$$

with initial value $\phi_{i}(0)=x_{i}(0)$. From Lemma 7 , we have

$$
\phi_{i}(t)=\frac{e^{\left(r_{i}-\left(\sigma_{i}^{2} / 2\right)\right) t+\sigma_{i} B_{i}(t)}}{\left(1 / x_{i}(0)\right)+a_{i i} \int_{0}^{t} e^{\left(r_{i}-\left(\sigma_{i}^{2} / 2\right)\right) s+\sigma_{i} B_{i}(s)} d s}, \quad t \geq 0
$$

From the result in [13], we know

$$
\begin{gathered}
\lim _{t \rightarrow \infty} \frac{1}{t} \int_{0}^{t} \phi_{i}(s) d s=\frac{r_{i}-\sigma_{i}^{2} / 2}{a_{i i}}, \\
\lim _{t \rightarrow \infty} \frac{\log \phi_{i}(t)}{t}=0, \quad \text { a.s. } i=1,2,3
\end{gathered}
$$

provided Assumption 2.

Theorem 9. Under Assumptions 1 and 2, system (9) is persistent in time average.

Proof. From Lemma 7, we know

$x_{i}(t)$

$$
\begin{gathered}
=\frac{e^{\int_{0}^{t}\left(r_{i}+\sum_{j=1, j \neq i}^{3} a_{i j} x_{j}(s-\tau)-\left(\sigma_{i}^{2} / 2\right)\right) d s+\sigma_{i} B_{i}(t)}}{\left(1 / x_{i}(0)\right)+a_{i i} \int_{0}^{t} e^{\int_{0}^{s}\left(r_{i}+\sum_{j=1, j \neq i}^{3} a_{i j} x_{j}(u-\tau)-\left(\sigma_{i}^{2} / 2\right)\right) d u+\sigma_{i} B_{i}(s)} d s} \\
=(1)\left(e^{-\sigma_{i} B_{i}(t)}\right. \\
\quad \times\left[\frac{1}{x_{i}(0)} e^{-\int_{0}^{t}\left(r_{i}+\sum_{j=1, j \neq i}^{3} a_{i j} x_{j}(s-\tau)-\left(\sigma_{i}^{2} / 2\right)\right) d s}+a_{i i}\right. \\
\left.\left.\quad \times \int_{0}^{t} e^{-\int_{s}^{t}\left(r_{i}+\sum_{j=1, j \neq i}^{3} a_{i j} x_{j}(u-\tau)-\left(\sigma_{i}^{2} / 2\right)\right) d u+\sigma_{i} B_{i}(s)} d s\right]\right)^{-1} .
\end{gathered}
$$

From Remark 8, yields

$$
x_{i}(t) \geq \phi_{i}(t), \quad i=1,2,3 .
$$

Together with Lemma 7, it is easy to obtain

$$
\begin{gathered}
\frac{r_{i}-\sigma_{i}^{2} / 2}{a_{i i}} \leq \liminf _{t \rightarrow \infty} \frac{1}{t} \int_{0}^{t} x_{i}(s) d s, \\
\liminf _{t \rightarrow \infty} \frac{\log x_{i}(t)}{t} \geq 0 \quad \text { a.s. } i=1,2,3 .
\end{gathered}
$$

The inequality $\limsup \sup _{t \rightarrow \infty}(1 / t) \int_{0}^{t} x_{i}(s) d s<+\infty$ a.s. $i=$ $1,2,3$ will be shown in Theorem 11 .

Theorem 9 shows that system (9) is persistent in time average if the intensity of noise is small. Next we want to obtain the limit of the solution in time average of system (9). We begin from the lemma in [29].

Lemma 10. Let $f \in C[[0, \infty) \times \Omega,(0, \infty)], F(t) \in((0, \infty) \times$ $\Omega, R)$. If there exist positive constants $\lambda_{0}$ and $\lambda$ such that

$$
\log f(t) \geq \lambda t-\lambda_{0} \int_{0}^{t} f(s) d s+F(t), \quad t \geq 0, \text { a.s. }
$$

and $\lim _{t \rightarrow \infty}(F(t) / t)=0$ a.s., then

$$
\liminf _{t \rightarrow \infty} \frac{1}{t} \int_{0}^{t} f(s) d s \geq \frac{\lambda}{\lambda_{0}}, \quad \text { a.s. }
$$


Theorem 11. Under Assumptions 1 and 2, for any initial data $\xi \in C\left([-\tau, 0] ; R_{+}^{3}\right)$, the solution $x(t, \xi)$ has the property that

$$
\lim _{t \rightarrow \infty} \frac{1}{t} \int_{0}^{t} x_{i}(s) d s=\tilde{x}_{i}^{*} \quad \text { a.s. } i=1,2,3,
$$

where

$$
\begin{aligned}
\tilde{x}_{1}^{*} & \left(\left(a_{22} a_{33}-a_{23} a_{32}\right)\left(r_{1}-\frac{\sigma_{1}^{2}}{2}\right)+\left(a_{12} a_{33}+a_{13} a_{32}\right)\right. \\
& \left.\times\left(r_{2}-\frac{\sigma_{2}^{2}}{2}\right)+\left(a_{12} a_{23}+a_{13} a_{22}\right)\left(r_{3}-\frac{\sigma_{3}^{2}}{2}\right)\right) \\
\times & \left(a_{11} a_{22} a_{33}-a_{11} a_{23} a_{32}-a_{22} a_{13} a_{31}\right. \\
\tilde{x}_{2}^{*} \quad & \left.\quad-a_{33} a_{12} a_{21}-a_{12} a_{23} a_{31}-a_{21} a_{32} a_{13}\right)^{-1}, \\
= & \left(a_{21} a_{33}+a_{23} a_{31}\right)\left(r_{1}-\frac{\sigma_{1}^{2}}{2}\right)+\left(a_{11} a_{33}-a_{13} a_{31}\right) \\
& \left.\times\left(r_{2}-\frac{\sigma_{2}^{2}}{2}\right)+\left(a_{11} a_{23}+a_{13} a_{21}\right)\left(r_{3}-\frac{\sigma_{3}^{2}}{2}\right)\right) \\
\times & \left(a_{11} a_{22} a_{33}-a_{11} a_{23} a_{32}-a_{22} a_{13} a_{31}\right. \\
& \left.-a_{33} a_{12} a_{21}-a_{12} a_{23} a_{31}-a_{21} a_{32} a_{13}\right)^{-1}, \\
\tilde{x}_{3}^{*} \quad & \left.\quad-a_{33} a_{12} a_{21}-a_{12} a_{23} a_{31}-a_{21} a_{32} a_{13}\right)^{-1} \cdot \\
= & \left(a_{21} a_{32}+a_{22} a_{31}\right)\left(r_{1}-\frac{\sigma_{1}^{2}}{2}\right)+\left(a_{11} a_{32}+a_{12} a_{31}\right) \\
& \left.\times\left(r_{2}-\frac{\sigma_{2}^{2}}{2}\right)+\left(a_{11} a_{22}-a_{12} a_{21}\right)\left(r_{3}-\frac{\sigma_{3}^{2}}{2}\right)\right) \\
\times & \left(a_{33}-a_{11} a_{23} a_{32}-a_{22} a_{13} a_{31}\right.
\end{aligned}
$$

The mathematical derivations are lengthy; we will give the proof in the appendix.

\section{Nonpersistence}

In this section, we will show that the system (9) is nonpersistent if the intensity of the noise is big enough; however, it does not occur to the deterministic system. First of all, we give the definition of nonpersistence.

Definition 12. System (9) is nonpersistent, if there are positive constants $b_{1}, b_{2}, b_{3}$ such that

$$
\lim _{t \rightarrow \infty} \prod_{i=1}^{3} x_{i}^{b_{i}}(t)=0 \quad \text { a.s. }
$$

Theorem 13. Under Assumption 1, if $C<0$ holds, system (9) is nonpersistent, where $C=b_{11}\left(r_{1}-\left(\sigma_{1}^{2} / 2\right)\right)+b_{12}\left(r_{2}-\left(\sigma_{2}^{2} / 2\right)\right)+$ $b_{13}\left(r_{3}-\left(\sigma_{3}^{2} / 2\right)\right), b_{11}>0 ; b_{12}, b_{13}$ is defined by (B.24).
Proof. It follows from (B.25) that

$$
\begin{aligned}
b_{11} & \log x_{1}(t)+b_{12} \log x_{2}(t)+b_{13} \log x_{3}(t) \\
\leq & \left(b_{11} \bar{r}_{1}+b_{12} \bar{r}_{2}+b_{13} \bar{r}_{3}\right) t \\
& \quad-m_{1} \int_{0}^{t} x_{1}(s) d s+\sum_{i=1}^{3} b_{1 i} \sigma_{i} B_{i}(t)+\sum_{i=1}^{3} b_{1 i} U_{i} \\
\leq & \left(b_{11} \bar{r}_{1}+b_{12} \bar{r}_{2}+b_{13} \bar{r}_{3}\right) t+\sum_{i=1}^{3} b_{1 i} \sigma_{i} B_{i}(t)+\sum_{i=1}^{3} b_{1 i} U_{i} .
\end{aligned}
$$

Together with $\lim _{t \rightarrow \infty}\left(B_{i}(t) / t\right)=0$ and $\lim _{t \rightarrow \infty}\left(U_{i} / t\right)=$ $0, i=1,2,3$, we have

$$
\limsup _{t \rightarrow \infty} \frac{1}{t} \sum_{i=1}^{3} b_{1 i} \log x_{i}(t) \leq b_{11} \bar{r}_{1}+b_{12} \bar{r}_{2}+b_{13} \bar{r}_{3} .
$$

If $b_{11} \bar{r}_{1}+b_{12} \bar{r}_{2}+b_{13} \bar{r}_{3}<0$ holds, it follows

$$
\lim _{t \rightarrow \infty} \prod_{i=1}^{3} x_{i}^{b_{1 i}}(t)=0 \quad \text { a.s. }
$$

Hence, system (9) is nonpersistent. The proof is completed.

By a similar method, we can yield the following theorems.

Theorem 14. Under Assumption 1, if $C<0$ holds, system (9) is nonpersistent, where $C=b_{21}\left(r_{1}-\left(\sigma_{1}^{2} / 2\right)\right)+b_{22}\left(r_{2}-\left(\sigma_{2}^{2} / 2\right)\right)+$ $b_{23}\left(r_{3}-\left(\sigma_{3}^{2} / 2\right)\right), b_{22}>0, b_{21}=\left(\left(-a_{21} a_{33}-a_{23} a_{31}\right) /\left(a_{13} a_{31}-\right.\right.$ $\left.\left.a_{11} a_{33}\right)\right) b_{22}, b_{23}=\left(\left(-a_{13} a_{21}-a_{11} a_{23}\right) /\left(a_{13} a_{31}-a_{11} a_{33}\right)\right) b_{22}$.

Theorem 15. Under Assumption 1, if $C<0$ holds, system (9) is nonpersistent, where $C=b_{31}\left(r_{1}-\left(\sigma_{1}^{2} / 2\right)\right)+b_{32}\left(r_{2}-\left(\sigma_{2}^{2} / 2\right)\right)+$ $b_{23}\left(r_{3}-\left(\sigma_{3}^{2} / 2\right)\right), b_{33}>0, b_{31}=\left(\left(-a_{31} a_{22}-a_{32} a_{21}\right) /\left(a_{12} a_{21}-\right.\right.$ $\left.\left.a_{11} a_{22}\right)\right) b_{33}, b_{32}=\left(\left(-a_{31} a_{12}-a_{32} a_{11}\right) /\left(a_{12} a_{21}-a_{11} a_{22}\right)\right) b_{33}$.

\section{Numerical Examinations}

In this section, we give the numerical examinations to illustrate above results. By the method mentioned in [30], consider the discrete equation:

$$
\begin{aligned}
x_{1, k+1}=x_{1, k}+x_{1, k} & {\left[\left(r_{1}-a_{11} x_{1, k}+a_{12} x_{2, k-m}+a_{13} x_{3, k-m}\right) \Delta t\right.} \\
+ & \left.\sigma_{1} \varepsilon_{1, k} \sqrt{\Delta t}+\frac{1}{2} \sigma_{1}^{2}\left(\varepsilon_{1, k}^{2} \Delta t-\Delta t\right)\right], \\
x_{2, k+1}=x_{2, k}+x_{2, k} & {\left[\left(r_{2}+a_{21} x_{1, k-m}-a_{22} x_{2, k}+a_{23} x_{3, k-m}\right) \Delta t\right.} \\
+ & \left.\sigma_{2} \varepsilon_{2, k} \sqrt{\Delta t}+\frac{1}{2} \sigma_{2}^{2}\left(\varepsilon_{2, k}^{2} \Delta t-\Delta t\right)\right], \\
x_{3, k+1}=x_{3, k}+x_{3, k} & {\left[\left(r_{3}+a_{31} x_{1, k-m}+a_{32} x_{2, k-m}-a_{33} x_{3, k}\right) \Delta t\right.} \\
+ & \left.\sigma_{3} \varepsilon_{3, k} \sqrt{\Delta t}+\frac{1}{2} \sigma_{3}^{2}\left(\varepsilon_{3, k}^{2} \Delta t-\Delta t\right)\right],
\end{aligned}
$$


where $m$ represents the integer part of $\tau / \Delta t-1$. Choosing suitable parameters in the system, by Matlab we get the simulation figures with initial value $\left(x_{1}(t), x_{2}(t), x_{3}(t)\right) \equiv$ $(0.7,0.3,0.9), t \in[-\tau, 0]$. (For convenience we let the initial value be a constant function; otherwise we have to give $m+1$ values.) The time step $\Delta t=0.005$; we always choose

$$
\begin{aligned}
\left(\begin{array}{lll}
a_{11} & a_{12} & a_{13} \\
a_{21} & a_{22} & a_{23} \\
a_{31} & a_{32} & a_{33}
\end{array}\right) & =\left(\begin{array}{lll}
0.7 & 0.2 & 0.4 \\
0.1 & 0.5 & 0.3 \\
0.2 & 0.4 & 0.8
\end{array}\right), \\
\left(\begin{array}{l}
r_{1} \\
r_{2} \\
r_{3}
\end{array}\right) & =\left(\begin{array}{l}
0.4 \\
0.2 \\
0.3
\end{array}\right) .
\end{aligned}
$$

Then $a_{11}-a_{12}-a_{13}=0.1, a_{22}-a_{21}-a_{23}=0.2, a_{33}-$ $a_{31}-a_{32}=0.2,\left(x_{1}^{*}, x_{2}^{*}, x_{3}^{*}\right)=(2.2679,2.0268,1.9554)$. By choosing different intensities of the noise and time delays, we obtain the following cases to illustrate our results.

Case 1 (persistence). Choosing $\tau=20.2 \sigma_{1}=0.04, \sigma_{2}=$ $0.08, \sigma_{3}=0.07$, then we have $r_{i}>\sigma_{i}^{2} / 2, i=1,2,3$. Hence all assumptions of Theorem 11 are satisfied. Figure 1 shows that the solution fluctuates in a small zone.

Case 2 (nonpersistence (we only illustrate the first situation)).

(1) $x_{1}(t)$ Is Disturbed by a Big Noise, Which Leads to Nonpersistence. Choosing $\tau=20.2, \sigma_{1}=1.53, \sigma_{2}=0.08, \sigma_{3}=$ $0.07, b_{11}=0.10, b_{12}=0.1143, b_{13}=0.0929$, then we have $r_{i}>\sigma_{i}^{2}, i=2,3$ but $b_{11}\left(r_{1}-\left(\sigma_{1}^{2} / 2\right)\right)+b_{12}\left(r_{2}-\left(\sigma_{2}^{2} / 2\right)\right)+b_{13}\left(r_{3}-\right.$ $\left.\left(\sigma_{3}^{2} / 2\right)\right)<0$. For convenience we shorten $b_{1 i}$ to $b_{i}$. Hence the assumptions of Theorem 13 are satisfied, and system (9) is nonpersistent (see Figure 2(d)). In addition, since $r_{i}>$ $\sigma_{i}^{2}, i=2,3, x_{2}(t), x_{3}(t)$ do not tend to zero in time average by Theorem 9. So $\lim _{t \rightarrow \infty} x_{1}(t)=0$ a.s. (see Figures $2(\mathrm{a})-2(\mathrm{c})$ ).

(2) The Second Specie $x_{2}(t)$ Is Disturbed by the Big White Noise, Which Leads to the Nonpersistence. Choosing $\tau=$ 20.2, $\sigma_{1}=0.04, \sigma_{2}=1.17, \sigma_{3}=0.07, b_{1}=0.10, b_{2}=$ $0.1143, b_{3}=0.0929$, then we have $r_{i}>\sigma_{i}^{2}, i=1,3$, but $b_{1}\left(r_{1}-\left(\sigma_{1}^{2} / 2\right)\right)+b_{2}\left(r_{2}-\left(\sigma_{2}^{2} / 2\right)\right)+b_{3}\left(r_{3}-\left(\sigma_{3}^{2} / 2\right)\right)<0$. Hence the assumptions of Theorem 13 are satisfied, and system (9) is nonpersistent (see Figure 3(d)). In addition, since $r_{i}>$ $\sigma_{i}^{2}, i=1,3, x_{1}(t), x_{3}(t)$ do not tend to zero in time average by Theorem 9. So $\lim _{t \rightarrow \infty} x_{2}(t)=0$ a.s. (see Figures 3(a)-3(c)).

(3) The Third Specie $x_{3}(t)$ Is Disturbed by the Big White Noise, Which Leads to the Nonpersistence. Choosing $\tau=20.2, \sigma_{1}=$ $0.04, \sigma_{2}=0.08, \sigma_{3}=1.36, b_{1}=0.10, b_{2}=0.1143, b_{3}=$ 0.0929 , then we have $r_{i}>\sigma_{i}^{2}, i=1,2$, but $b_{1}\left(r_{1}-\left(\sigma_{1}^{2} / 2\right)\right)+$ $b_{2}\left(r_{2}-\left(\sigma_{2}^{2} / 2\right)\right)+b_{3}\left(r_{3}-\left(\sigma_{3}^{2} / 2\right)\right)<0$. Hence the assumptions of Theorem 13 are satisfied, and system (9) is nonpersistent (see Figure $4(\mathrm{~d})$ ). In addition, since $r_{i}>\sigma_{i}^{2}, i=1,2$, $x_{1}(t), x_{2}(t)$ do not tend to zero in time average by Theorem 9 . So we have $\lim _{t \rightarrow \infty} x_{3}(t)=0$ a.s. (see Figures $4(a)-4(c)$ ).
(4) The First Two Species $x_{1}(t), x_{2}(t)$ Are Disturbed by the Big White Noises, Which Leads to the Nonpersistence. Choosing $\tau=20.2, \sigma_{1}=1.25, \sigma_{2}=1.01, \sigma_{3}=0.07, b_{1}=0.10, b_{2}=$ $0.1143, b_{3}=0.0929$, then we have $r_{3}>\sigma_{3}^{2}$, but $b_{1}\left(r_{1}-\left(\sigma_{1}^{2} / 2\right)\right)+$ $b_{2}\left(r_{2}-\left(\sigma_{2}^{2} / 2\right)\right)+b_{3}\left(r_{3}-\left(\sigma_{3}^{2} / 2\right)\right)<0$. Hence the assumptions of Theorem 13 are satisfied; then system (9) is nonpersistent (see Figure 5(d)). In addition, since $r_{3}>\sigma_{3}^{2}, x_{3}(t)$ does not tend to zero in time average by Theorem 9 . So we have $\lim _{t \rightarrow \infty} x_{i}(t)=0, i=1,2$ a.s. (see Figures 5(a)-5(c)).

(5) The First and the Third Species $x_{1}(t), x_{3}(t)$ Are Disturbed by the Big White Noises, Which Leads to the Nonpersistence. Choosing $\tau=20.2, \sigma_{1}=1.25, \sigma_{2}=0.08, \sigma_{3}=1.12, b_{1}=$ $0.10, b_{2}=0.1143, b_{3}=0.0929$, then we have $r_{2}>\sigma_{2}^{2}$, but $b_{1}\left(r_{1}-\left(\sigma_{1}^{2} / 2\right)\right)+b_{2}\left(r_{2}-\left(\sigma_{2}^{2} / 2\right)\right)+b_{3}\left(r_{3}-\left(\sigma_{3}^{2} / 2\right)\right)<$ 0 . Hence the assumptions of Theorem 13 are satisfied, and system (9) is nonpersistent (see Figure 6(d)). In addition, since $r_{2}>\sigma_{2}^{2}, x_{2}(t)$ does not tend to zero in time average by Theorem 9 . So we have $\lim _{t \rightarrow \infty} x_{i}(t)=0, i=1,3$ a.s. (see Figures 6(a)-6(c)).

(6) The Last Two Species $x_{2}(t), x_{3}(t)$ Are Disturbed by the Big White Noises, Which Leads to Nompersistence. Choosing $\tau=20.2, \sigma_{1}=0.04, \sigma_{2}=1.17, \sigma_{3}=1.36, b_{1}=0.10, b_{2}=$ $0.1143, b_{3}=0.0929$, then we have $r_{1}>\sigma_{1}^{2}$, but $b_{1}\left(r_{1}-\left(\sigma_{1}^{2} / 2\right)\right)+$ $b_{2}\left(r_{2}-\left(\sigma_{2}^{2} / 2\right)\right)+b_{3}\left(r_{3}-\left(\sigma_{3}^{2} / 2\right)\right)<0$. Hence the assumptions of Theorem 13 are satisfied, and system (9) is nonpersistent (see Figure $7(\mathrm{~d})$ ). In addition, since $r_{1}>\sigma_{1}^{2}, x_{1}(t)$ does not tend to zero in time average by Theorem 9 . So we have $\lim _{t \rightarrow \infty} x_{i}(t)=0, i=2,3$ a.s. (see Figures $7(\mathrm{a})-7(\mathrm{c})$ ).

(7) All the Three Species $x_{1}(t), x_{2}(t), x_{3}(t)$ Are Disturbed by the Big White Noise, Which Leads to the Nonpersistence. Choosing $\tau=20.2, \sigma_{1}=1.25, \sigma_{1}=1.01, \sigma_{1}=1.36, b_{1}=0.10, b_{2}=$ $0.1143, b_{3}=0.0929$, then we have $b_{1}\left(r_{1}-\left(\sigma_{1}^{2} / 2\right)\right)+b_{2}\left(r_{2}-\right.$ $\left.\left(\sigma_{2}^{2} / 2\right)\right)+b_{3}\left(r_{3}-\left(\sigma_{3}^{2} / 2\right)\right)<0$. Hence the assumptions of Theorem 13 are satisfied, and system (9) is nonpersistent (see Figure $8(\mathrm{~d}))$. So we have $\lim _{t \rightarrow \infty} x_{i}(t)=0, i=1,2,3$ a.s. (see Figures $8(a)-8(c)$ ).

\section{Appendices}

\section{A. Proof of Theorem 5}

Proof. Define a $C^{2}$ function $V_{1}: R_{+}^{3} \rightarrow R_{+}$by

$$
\begin{aligned}
V_{1}\left(x_{1}, x_{2}, x_{3}\right)= & c_{1}\left[x_{1}(t)-x_{1}^{*}-x_{1}^{*} \log \frac{x_{1}(t)}{x_{1}^{*}}\right] \\
& +c_{2}\left[x_{2}(t)-x_{2}^{*}-x_{2}^{*} \log \frac{x_{2}(t)}{x_{2}^{*}}\right] \\
& +c_{3}\left[x_{3}(t)-x_{3}^{*}-x_{3}^{*} \log \frac{x_{3}(t)}{x_{3}^{*}}\right] .
\end{aligned}
$$


$x_{1}(t)$

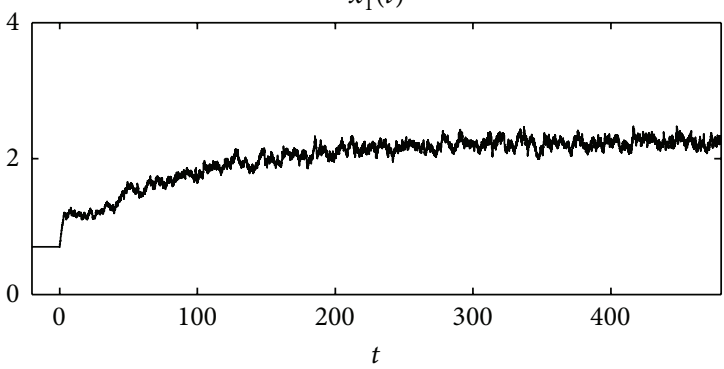

(a)

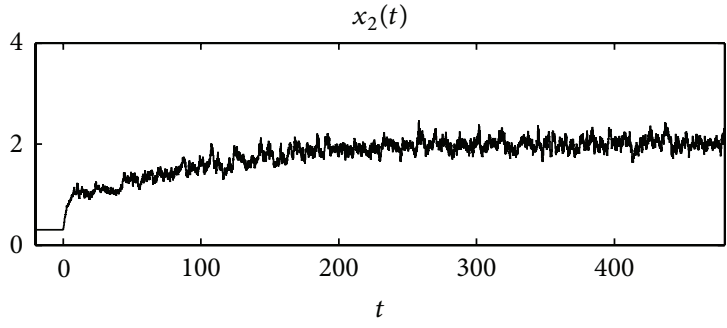

(c)

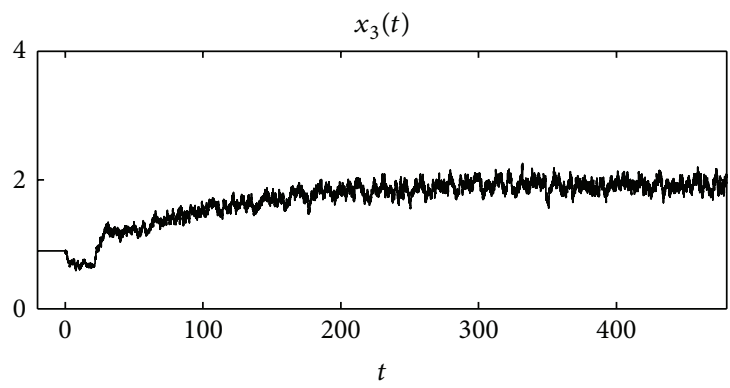

(e)

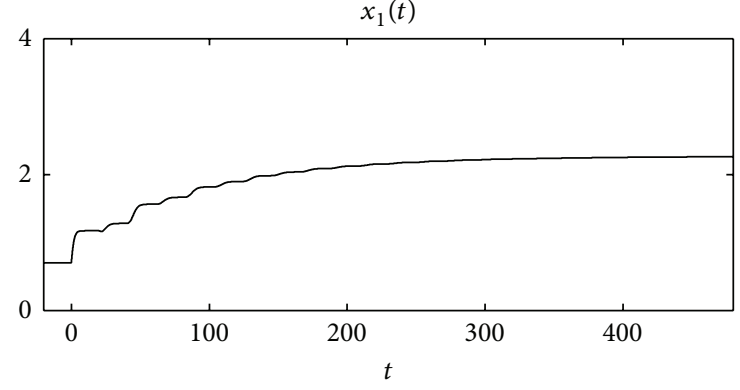

(b)

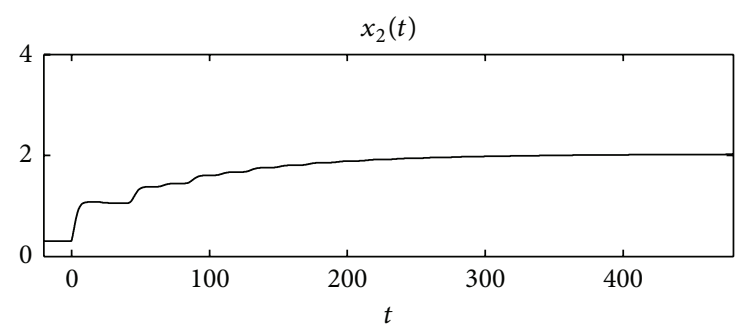

(d)

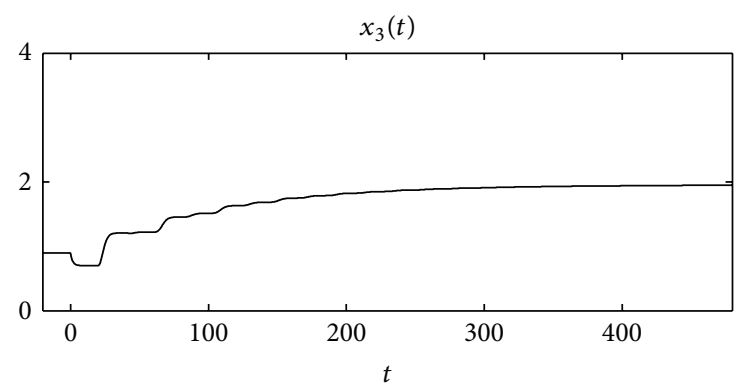

(f)

FIGURE 1: The solution (imaginary line) of system (8) and the solution (real line) of system (9) with $\sigma_{1}=0.04, \sigma_{2}=0.08, \sigma_{3}=0.07, \Delta t=0.005$.

By Itô's formula, we have

$$
\begin{aligned}
& d V_{1}\left(x_{1}, x_{2}, x_{3}\right) \\
& =c_{1}\left[1-\frac{x_{1}^{*}}{x_{1}(t)}\right] d x_{1}(t)+c_{2}\left[1-\frac{x_{2}^{*}}{x_{2}(t)}\right] d x_{2}(t) \\
& +c_{3}\left[1-\frac{x_{3}^{*}}{x_{3}(t)}\right] d x_{3}(t)+\frac{c_{1}}{2} x_{1}^{*} \sigma_{1}^{2} d t \\
& +\frac{c_{2}}{2} x_{2}^{*} \sigma_{2}^{2} d t+\frac{c_{3}}{2} x_{3}^{*} \sigma_{3}^{2} d t \\
& =c_{1}\left[x_{1}(t)-x_{1}^{*}\right]\left[\left(r_{1}-a_{11} x_{1}(t)+a_{12} x_{2}(t-\tau)\right.\right. \\
& \left.\left.\quad+a_{13} x_{3}(t-\tau)\right) d t+\sigma_{1} d B_{1}(t)\right] \\
& +c_{2}\left[x_{2}(t)-x_{2}^{*}\right]\left[\left(r_{2}+a_{21} x_{1}(t-\tau)-a_{22} x_{2}(t)\right.\right. \\
& \left.\left.\quad+a_{23} x_{3}(t-\tau)\right) d t+\sigma_{2} d B_{2}(t)\right] \\
& +c_{3}\left[x_{3}(t)-x_{3}^{*}\right]\left[\left(r_{3}+a_{31} x_{1}(t-\tau)+a_{32} x_{2}(t-\tau)\right.\right.
\end{aligned}
$$

$$
\left.\left.-a_{33} x_{3}(t)\right) d t+\sigma_{3} d B_{3}(t)\right]
$$$$
+\left(\frac{c_{1}}{2} x_{1}^{*} \sigma_{1}^{2}+\frac{c_{2}}{2} x_{2}^{*} \sigma_{2}^{2}+\frac{c_{3}}{2} x_{3}^{*} \sigma_{3}^{2}\right) d t
$$

where

$$
\begin{aligned}
& L V_{1}\left(x_{1}, x_{2}, x_{3}\right) \\
& =c_{1}\left[x_{1}(t)-x_{1}^{*}\right]\left[r_{1}-a_{11} x_{1}(t)\right. \\
& \left.+a_{12} x_{2}(t-\tau)+a_{13} x_{3}(t-\tau)\right] \\
& +c_{2}\left[x_{2}(t)-x_{2}^{*}\right]\left[r_{2}+a_{21} x_{1}(t-\tau)\right. \\
& \left.-a_{22} x_{2}(t)+a_{23} x_{3}(t-\tau)\right] \\
& +c_{3}\left[x_{3}(t)-x_{3}^{*}\right]\left[r_{3}+a_{31} x_{1}(t-\tau)\right. \\
& \left.+a_{32} x_{2}(t-\tau)-a_{33} x_{3}(t)\right] \\
& +\frac{c_{1} x_{1}^{*} \sigma_{1}^{2}+c_{2} x_{2}^{*} \sigma_{2}^{2}+c_{3} x_{3}^{*} \sigma_{3}^{2}}{2} \text {. }
\end{aligned}
$$




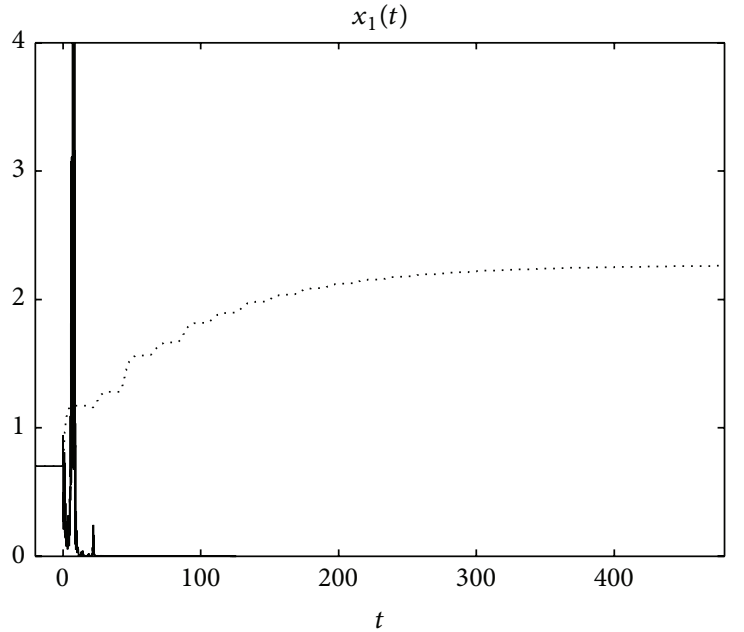

(a)

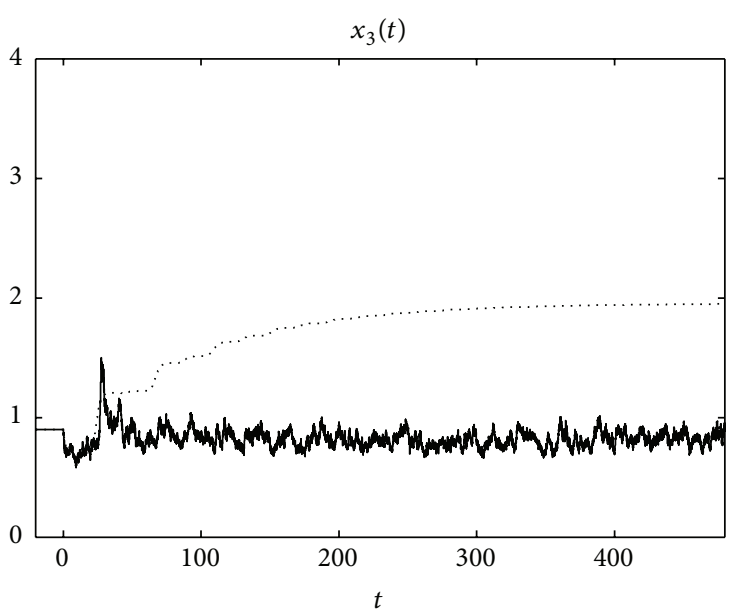

(c)

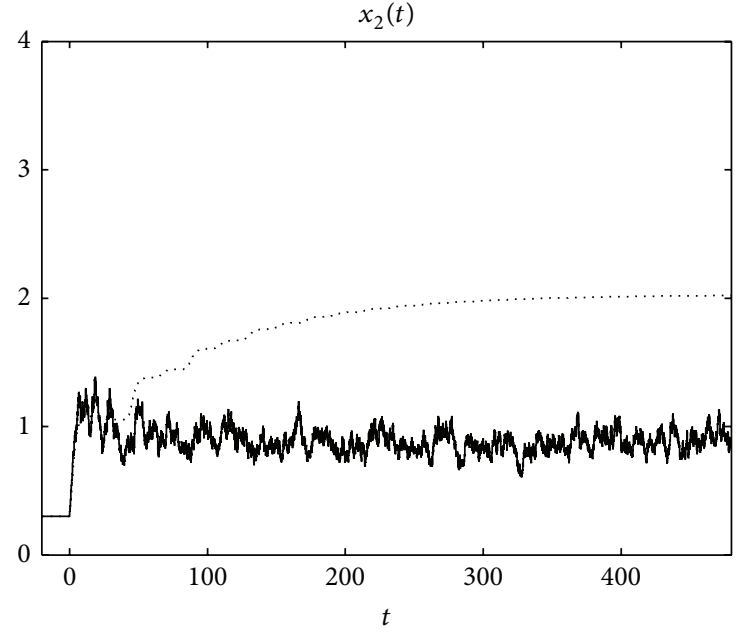

(b)

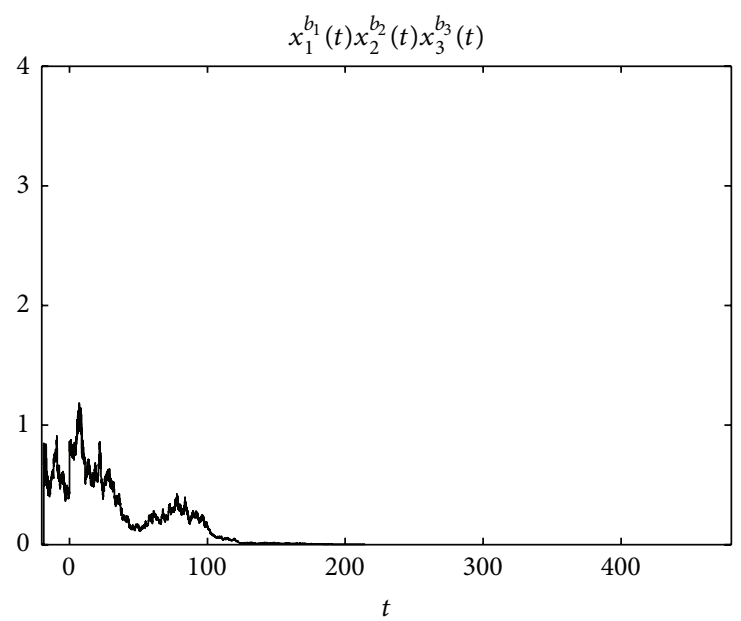

(d)

FIGURE 2: The solution (imaginary line) of system (8) and the solution (real line) of system (9) with $\sigma_{1}=1.53, \sigma_{2}=0.08, \sigma_{3}=0.07, \Delta t=$ 0.005 .

Since $x^{*}=\left(x_{1}^{*}, x_{2}^{*}, x_{3}^{*}\right)$ is the equilibrium point of system (8), we have

$$
\begin{aligned}
& L V_{1}\left(x_{1}, x_{2}, x_{3}\right) \\
& \begin{aligned}
c_{1}\left[x_{1}(t)-x_{1}^{*}\right][ & -a_{11}\left(x_{1}(t)-x_{1}^{*}\right)+a_{12}\left(x_{2}(t-\tau)-x_{2}^{*}\right) \\
+ & \left.a_{13}\left(x_{3}(t-\tau)-x_{3}^{*}\right)\right] \\
+c_{2}\left[x_{2}(t)-x_{2}^{*}\right][ & {\left[a_{21}\left(x_{1}(t-\tau)-x_{1}^{*}\right)-a_{22}\left(x_{2}(t)-x_{2}^{*}\right)\right.} \\
+ & \left.a_{23}\left(x_{3}(t-\tau)-x_{3}^{*}\right)\right] \\
+c_{3}\left[x_{3}(t)-x_{3}^{*}\right] & {\left[a_{31}\left(x_{1}(t-\tau)-x_{1}^{*}\right)\right.} \\
& +a_{32}\left(x_{2}(t-\tau)-x_{2}^{*}\right) \\
& \left.-a_{33}\left(x_{3}(t)-x_{3}^{*}\right)\right]
\end{aligned}
\end{aligned}
$$

$+\frac{c_{1} x_{1}^{*} \sigma_{1}^{2}+c_{2} x_{2}^{*} \sigma_{2}^{2}+c_{3} x_{3}^{*} \sigma_{3}^{2}}{2}$ $=-a_{11} c_{1}\left[x_{1}(t)-x_{1}^{*}\right]^{2}+a_{12} c_{1}\left[x_{1}(t)-x_{1}^{*}\right]\left[x_{2}(t-\tau)-x_{2}^{*}\right]$

$+a_{13} c_{1}\left[x_{1}(t)-x_{1}^{*}\right]\left[x_{3}(t-\tau)-x_{3}^{*}\right]$

$+a_{21} c_{2}\left[x_{2}(t)-x_{2}^{*}\right]\left[x_{1}(t-\tau)-x_{1}^{*}\right]$

$-a_{22} c_{2}\left[x_{2}(t)-x_{2}^{*}\right]^{2}+a_{23} c_{2}\left[x_{2}(t)-x_{2}^{*}\right]\left[x_{3}(t-\tau)-x_{3}^{*}\right]$

$+a_{31} c_{3}\left[x_{3}(t)-x_{3}^{*}\right]\left[x_{1}(t-\tau)-x_{1}^{*}\right]$

$+a_{32} c_{3}\left[x_{3}(t)-x_{3}^{*}\right]\left[x_{2}(t-\tau)-x_{2}^{*}\right]$

$-a_{33} c_{3}\left[x_{3}(t)-x_{3}^{*}\right]^{2}$

$+\frac{c_{1} x_{1}^{*} \sigma_{1}^{2}+c_{2} x_{2}^{*} \sigma_{2}^{2}+c_{3} x_{3}^{*} \sigma_{3}^{2}}{2}$. 


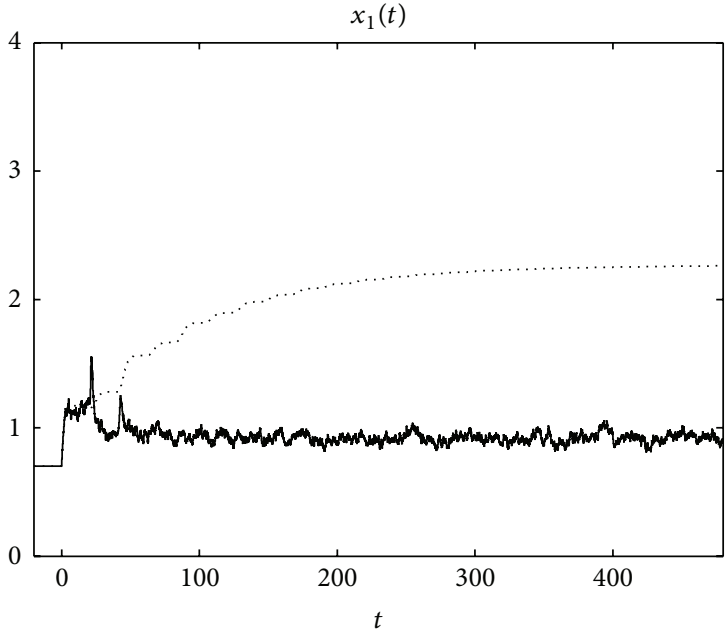

(a)

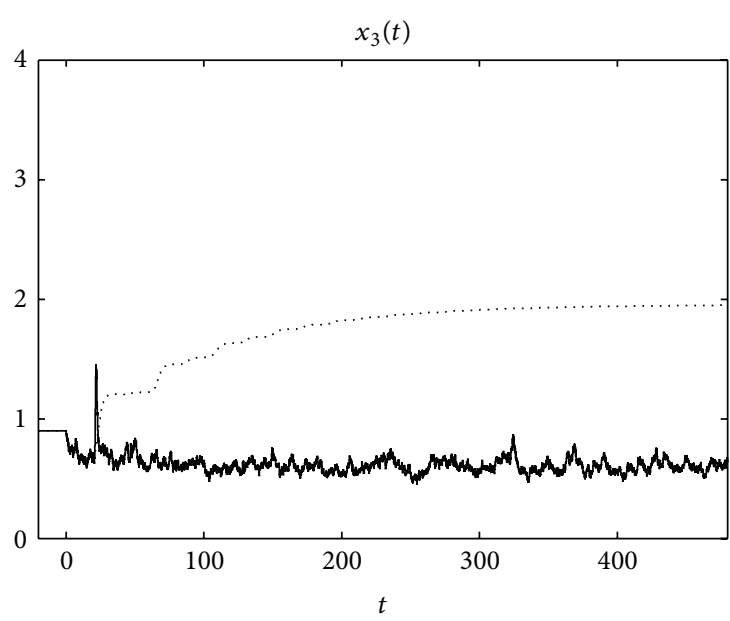

(c)

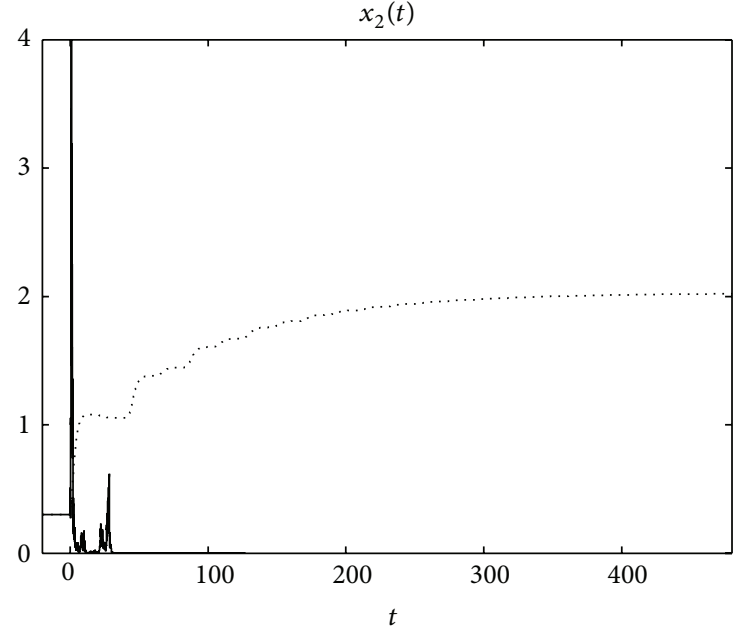

(b)

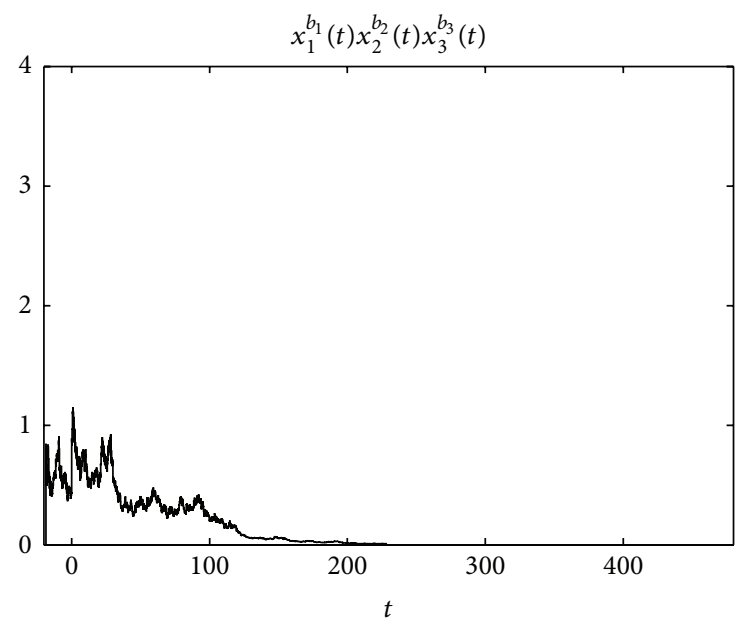

(d)

FIGURE 3: The solution (imaginary line) of system (8) and the solution (real line) of system (9) with $\sigma_{1}=0.04, \sigma_{2}=1.17, \sigma_{3}=0.07, \Delta t=$ 0.005 .

By Young inequality, we have

$$
\begin{aligned}
& a_{12} c_{1}\left[x_{1}(t)-x_{1}^{*}\right]\left[x_{2}(t-\tau)-x_{2}^{*}\right] \\
& \quad \leq \frac{a_{12} c_{1}}{2}\left\{\left(x_{1}(t)-x_{1}^{*}\right)^{2}+\left[x_{2}(t-\tau)-x_{2}^{*}\right]^{2}\right\}, \\
& a_{13} c_{1}\left[x_{1}(t)-x_{1}^{*}\right]\left[x_{3}(t-\tau)-x_{3}^{*}\right] \\
& \quad \leq \frac{a_{13} c_{1}}{2}\left\{\left(x_{1}(t)-x_{1}^{*}\right)^{2}+\left[x_{3}(t-\tau)-x_{3}^{*}\right]^{2}\right\}, \\
& a_{21} c_{2}\left[x_{2}(t)-x_{2}^{*}\right]\left[x_{1}(t-\tau)-x_{1}^{*}\right] \\
& \quad \leq \frac{a_{21} c_{2}}{2}\left\{\left(x_{2}(t)-x_{2}^{*}\right)^{2}+\left[x_{1}(t-\tau)-x_{1}^{*}\right]^{2}\right\}, \\
& a_{23} c_{2}\left[x_{2}(t)-x_{2}^{*}\right]\left[x_{3}(t-\tau)-x_{3}^{*}\right] \\
& \quad \leq \frac{a_{23} c_{2}}{2}\left\{\left(x_{2}(t)-x_{2}^{*}\right)^{2}+\left[x_{3}(t-\tau)-x_{3}^{*}\right]^{2}\right\}, \\
& a_{31} c_{3}\left[x_{3}(t)-x_{3}^{*}\right]\left[x_{1}(t-\tau)-x_{1}^{*}\right]
\end{aligned}
$$

$$
\begin{aligned}
& \quad \leq \frac{a_{23} c_{3}}{2}\left\{\left(x_{3}(t)-x_{3}^{*}\right)^{2}+\left[x_{1}(t-\tau)-x_{1}^{*}\right]^{2}\right\}, \\
& a_{32} c_{3}\left[x_{3}(t)-x_{3}^{*}\right]\left[x_{2}(t-\tau)-x_{2}^{*}\right] \\
& \quad \leq \frac{a_{32} c_{3}}{2}\left\{\left(x_{3}(t)-x_{3}^{*}\right)^{2}+\left[x_{2}(t-\tau)-x_{2}^{*}\right]^{2}\right\} .
\end{aligned}
$$

Substituting (A.5) into (A.4), we yield

$$
\begin{aligned}
& L V_{1}\left(x_{1}, x_{2}, x_{3}\right) \\
& \leq\left(-a_{11} c_{1}+\frac{a_{12} c_{1}}{2}+\frac{a_{13} c_{1}}{2}\right)\left[x_{1}(t)-x_{1}^{*}\right]^{2} \\
& \quad+\left(-a_{22} c_{2}+\frac{a_{21} c_{2}}{2}+\frac{a_{23} c_{2}}{2}\right)\left[x_{2}(t)-x_{2}^{*}\right]^{2} \\
& \quad+\left(-a_{33} c_{3}+\frac{a_{31} c_{3}}{2}+\frac{a_{32} c_{3}}{2}\right)\left[x_{3}(t)-x_{3}^{*}\right]^{2}
\end{aligned}
$$




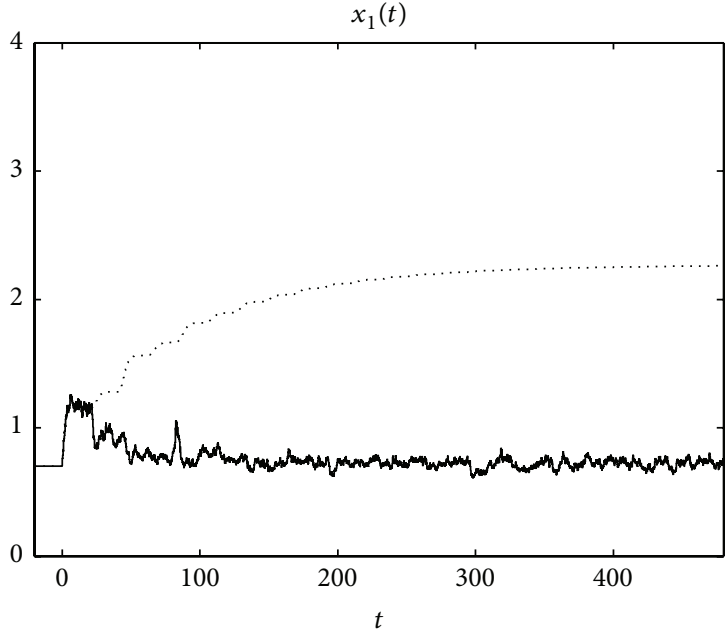

(a)

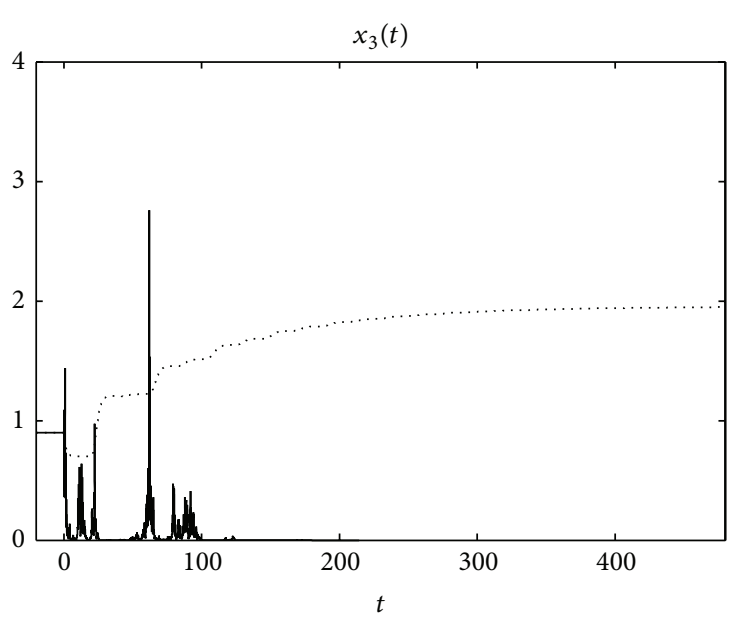

(c)

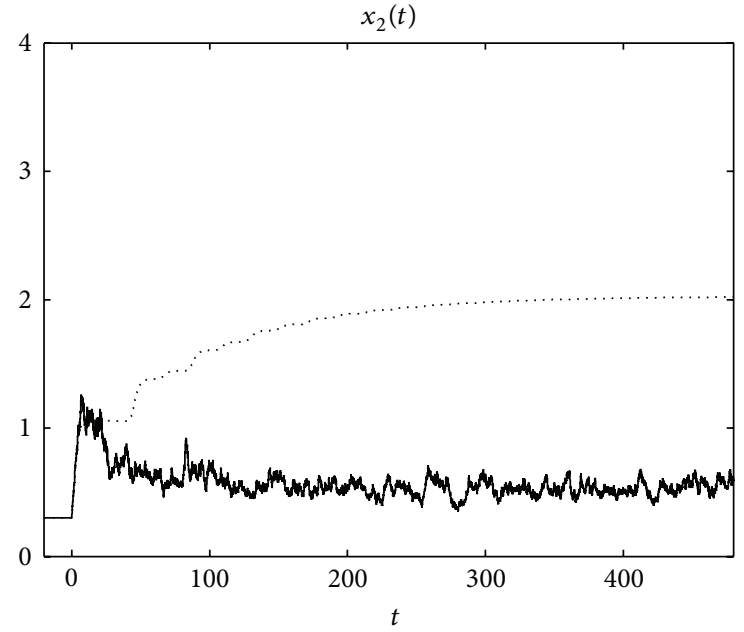

(b)

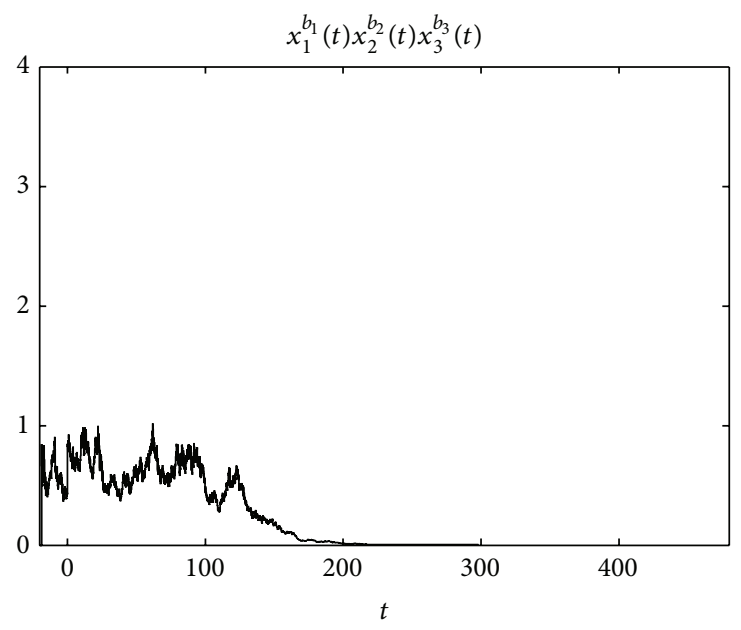

(d)

FIGURE 4: The solution (imaginary line) of system (8) and the solution (real line) of system (9) with $\sigma_{1}=0.04, \sigma_{2}=0.08, \sigma_{3}=1.36, \Delta t=$ 0.005 .

$$
\begin{aligned}
& +\left(\frac{a_{21} c_{2}}{2}+\frac{a_{31} c_{3}}{2}\right)\left[x_{1}(t-\tau)-x_{1}^{*}\right]^{2} \\
& +\left(\frac{a_{12} c_{1}}{2}+\frac{a_{32} c_{3}}{2}\right)\left[x_{2}(t-\tau)-x_{2}^{*}\right]^{2} \\
& +\left(\frac{a_{13} c_{1}}{2}+\frac{a_{23} c_{2}}{2}\right)\left[x_{3}(t-\tau)-x_{3}^{*}\right]^{2} \\
& +\frac{c_{1} x_{1}^{*} \sigma_{1}^{2}+c_{2} x_{2}^{*} \sigma_{2}^{2}+c_{3} x_{3}^{*} \sigma_{3}^{2}}{2} .
\end{aligned}
$$

From (A.6), we have

$$
\begin{aligned}
& d V_{1}\left(x_{1}, x_{2}, x_{3}\right) \\
& \leq\left\{\left(-a_{11} c_{1}+\frac{a_{12} c_{1}}{2}+\frac{a_{13} c_{1}}{2}\right)\left[x_{1}(t)-x_{1}^{*}\right]^{2}\right. \\
& +\left(-a_{22} c_{2}+\frac{a_{21} c_{2}}{2}+\frac{a_{23} c_{2}}{2}\right)\left[x_{2}(t)-x_{2}^{*}\right]^{2} \\
& +\left(-a_{33} c_{3}+\frac{a_{31} c_{3}}{2}+\frac{a_{32} c_{3}}{2}\right)\left[x_{3}(t)-x_{3}^{*}\right]^{2}
\end{aligned}
$$

$$
\begin{aligned}
& +\left(\frac{a_{21} c_{2}}{2}+\frac{a_{31} c_{3}}{2}\right)\left[x_{1}(t-\tau)-x_{1}^{*}\right]^{2} \\
& +\left(\frac{a_{12} c_{1}}{2}+\frac{a_{32} c_{3}}{2}\right)\left[x_{2}(t-\tau)-x_{2}^{*}\right]^{2} \\
& +\left(\frac{a_{13} c_{1}}{2}+\frac{a_{23} c_{2}}{2}\right)\left[x_{3}(t-\tau)-x_{3}^{*}\right]^{2} \\
& \left.+\frac{c_{1} x_{1}^{*} \sigma_{1}^{2}+c_{2} x_{2}^{*} \sigma_{2}^{2}+c_{3} x_{3}^{*} \sigma_{3}^{2}}{2}\right\} d t+\sum_{i=1}^{3} \sigma_{i} d B_{i} .
\end{aligned}
$$

Define

$$
\begin{aligned}
V_{2} & \left(x_{1}, x_{2}, x_{3}\right) \\
& =\int_{t}^{t+\tau}\left\{\left(\frac{a_{12} c_{1}}{2}+\frac{a_{32} c_{3}}{2}\right)\left[x_{2}(s-\tau)-x_{2}^{*}\right]^{2}\right.
\end{aligned}
$$




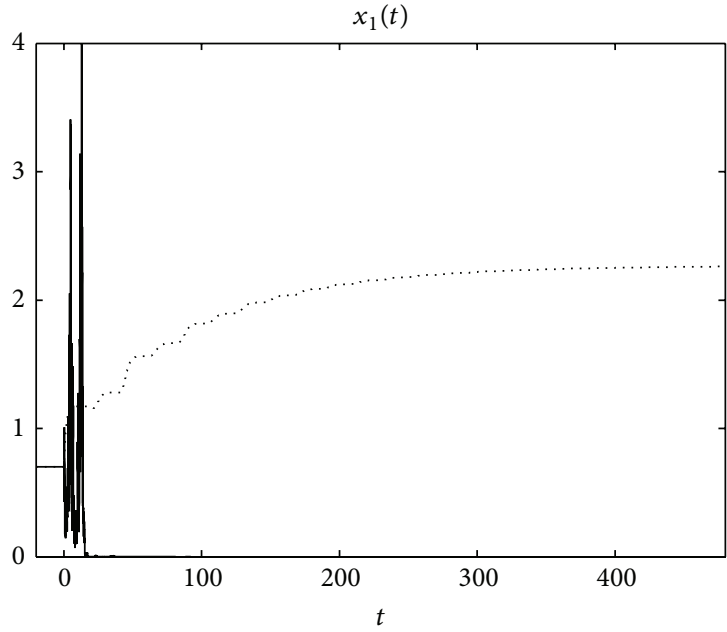

(a)

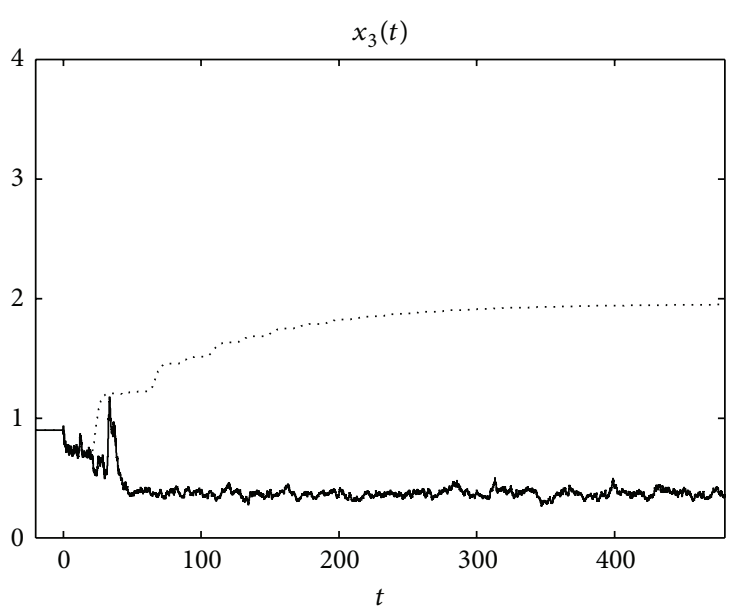

(c)

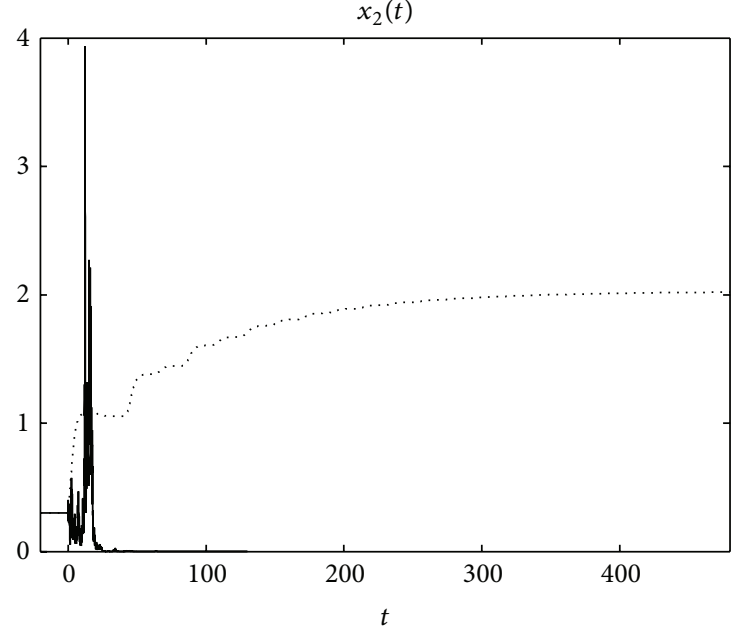

(b)

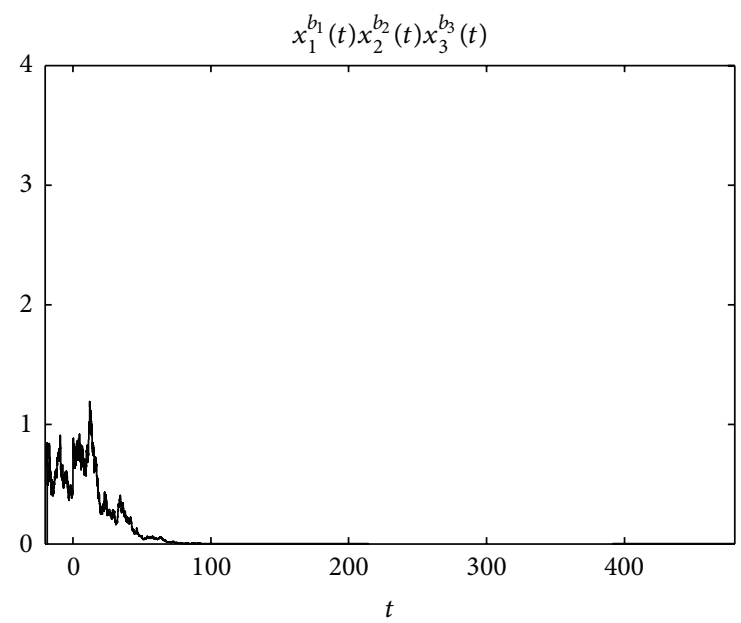

(d)

FIGURE 5: The solution (imaginary line) of system (8) and the solution (real line) of system (9) with $\sigma_{1}=1.25, \sigma_{2}=1.01, \sigma_{3}=0.07, \Delta t=$ 0.005 .

$$
\begin{aligned}
& +\left(\frac{a_{13} c_{1}}{2}+\frac{a_{23} c_{2}}{2}\right)\left[x_{3}(s-\tau)-x_{3}^{*}\right]^{2} \\
& \left.+\left(\frac{a_{21} c_{2}}{2}+\frac{a_{31} c_{3}}{2}\right)\left[x_{1}(s-\tau)-x_{1}^{*}\right]^{2}\right\} d s .
\end{aligned}
$$

$$
\begin{aligned}
& -\left(\frac{a_{13} c_{1}}{2}+\frac{a_{23} c_{2}}{2}\right)\left[x_{3}(t-\tau)-x_{3}^{*}\right]^{2} \\
& \left.-\left(\frac{a_{21} c_{2}}{2}+\frac{a_{31} c_{3}}{2}\right)\left[x_{1}(t-\tau)-x_{1}^{*}\right]^{2}\right\} d t .
\end{aligned}
$$

Then by Itô's formula, we have

$$
\begin{aligned}
& d V_{2}\left(x_{1}, x_{2}, x_{3}\right) \\
& =\left\{\left(\frac{a_{12} c_{1}}{2}+\frac{a_{32} c_{3}}{2}\right)\left[x_{2}(t)-x_{2}^{*}\right]^{2}\right. \\
& +\left(\frac{a_{13} c_{1}}{2}+\frac{a_{23} c_{2}}{2}\right)\left[x_{3}(t)-x_{3}^{*}\right]^{2} \\
& +\left(\frac{a_{21} c_{2}}{2}+\frac{a_{31} c_{3}}{2}\right)+\left[x_{1}(t)-x_{1}^{*}\right]^{2} \\
& \quad-\left(\frac{a_{12} c_{1}}{2}+\frac{a_{32} c_{3}}{2}\right)\left[x_{2}(t-\tau)-x_{2}^{*}\right]^{2}
\end{aligned}
$$

Define

$$
V\left(x_{1}, x_{2}, x_{3}\right)=V_{1}\left(x_{1}, x_{2}, x_{3}\right)+V_{2}\left(x_{1}, x_{2}, x_{3}\right)
$$

Together with (A.7) and (A.9), it implies

$$
\begin{aligned}
& d V\left(x_{1}, x_{2}, x_{3}\right) \\
& \leq\left\{\frac{\left(a_{12}+a_{13}-a_{11}\right) c_{1}-1}{2}\left[x_{1}(t)-x_{1}^{*}\right]^{2}\right. \\
& +\frac{\left(a_{21}+a_{23}-a_{22}\right) c_{2}-1}{2}\left[x_{2}(t)-x_{2}^{*}\right]^{2}
\end{aligned}
$$




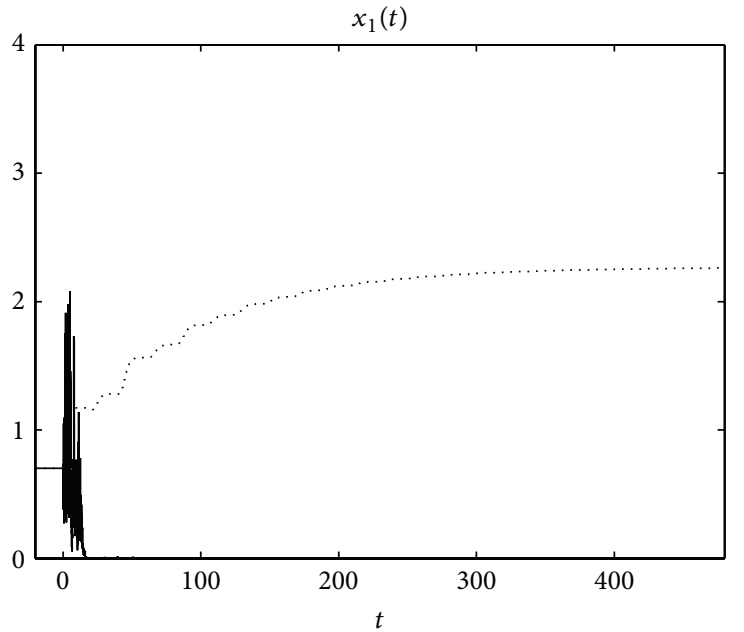

(a)

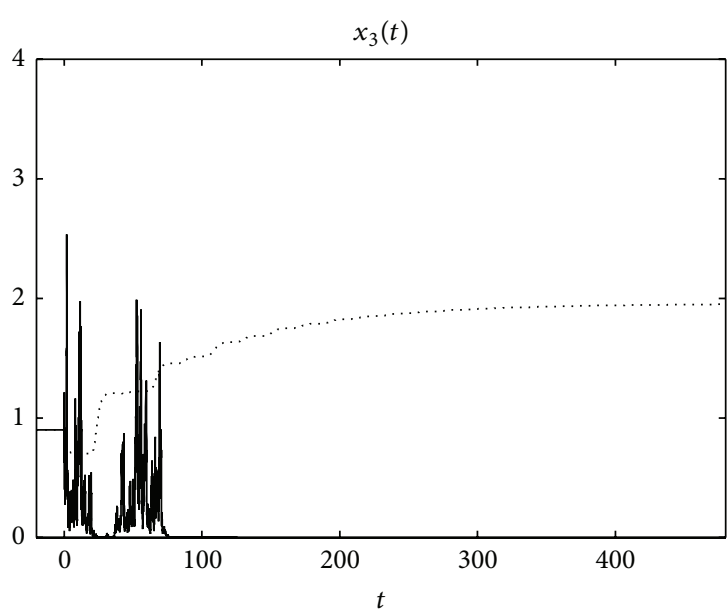

(c)

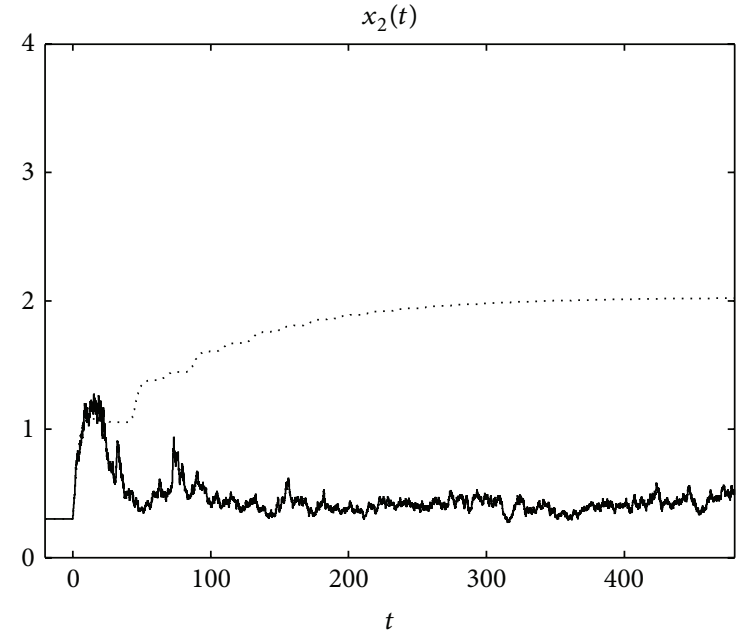

(b)

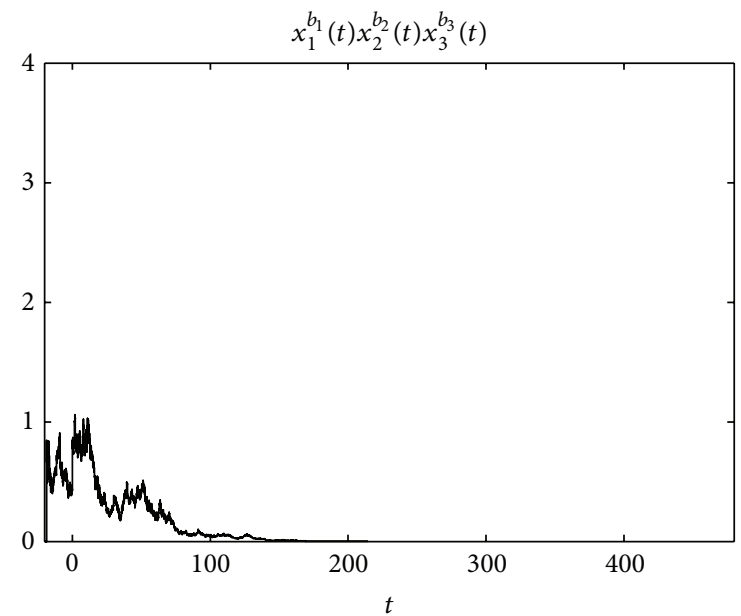

(d)

FIGURE 6: The solution (imaginary line) of system (8) and the solution (real line) of system (9) with $\sigma_{1}=1.25, \sigma_{2}=0.08, \sigma_{3}=1.12, \Delta t=$ 0.005 .

$$
\begin{aligned}
& +\frac{\left(a_{31}+a_{32}-a_{33}\right) c_{3}-1}{2}\left[x_{3}(t)-x_{3}^{*}\right]^{2} \\
& \left.+\frac{c_{1} x_{1}^{*} \sigma_{1}^{2}+c_{2} x_{2}^{*} \sigma_{2}^{2}+c_{3} x_{3}^{*} \sigma_{3}^{2}}{2}\right\} d t+\sum_{i=1}^{3} \sigma_{i} d B_{i} .
\end{aligned}
$$

Integrating from 0 to $t$, taking the expectation, we have

$$
\begin{aligned}
& E[V(t)]-V(0) \\
& \quad \leq-E \int_{0}^{t}\left\{\frac{\left(a_{11}-a_{12}-a_{13}\right) c_{1}+1}{2}\left[x_{1}(s)-x_{1}^{*}\right]^{2}\right.
\end{aligned}
$$

$$
\begin{aligned}
& +\frac{\left(a_{22}-a_{21}-a_{23}\right) c_{2}+1}{2}\left[x_{2}(s)-x_{2}^{*}\right]^{2} \\
& \left.+\frac{\left(a_{33}-a_{31}-a_{32}\right) c_{3}+1}{2}\left[x_{3}(s)-x_{3}^{*}\right]^{2}\right\} d s \\
& +\frac{c_{1} x_{1}^{*} \sigma_{1}^{2}+c_{2} x_{2}^{*} \sigma_{2}^{2}+c_{3} x_{3}^{*} \sigma_{3}^{2}}{2} t .
\end{aligned}
$$

Then we yield

$$
\begin{aligned}
\frac{E[V(t)]}{t} \leq & \frac{V(0)}{t} \\
& -\frac{\left(a_{11}-a_{12}-a_{13}\right) c_{1}+1}{2} E \frac{1}{t} \int_{0}^{t}\left[x_{1}(s)-x_{1}^{*}\right]^{2} d s
\end{aligned}
$$




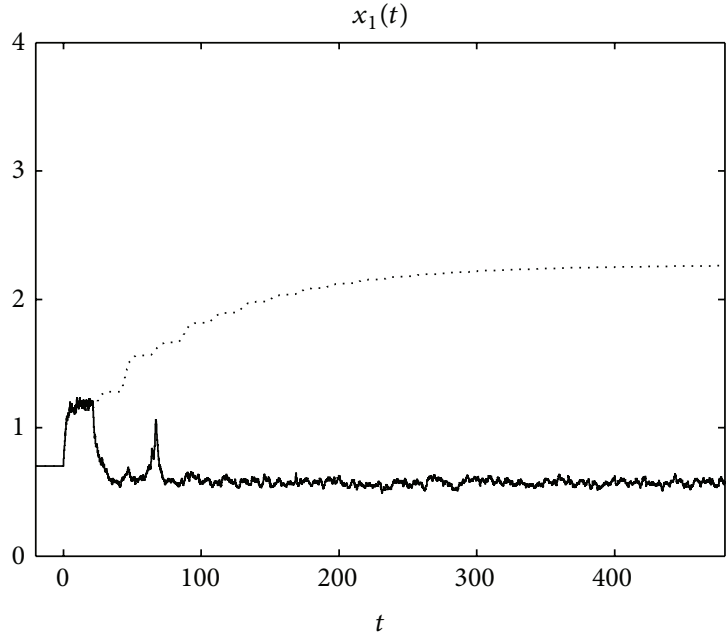

(a)

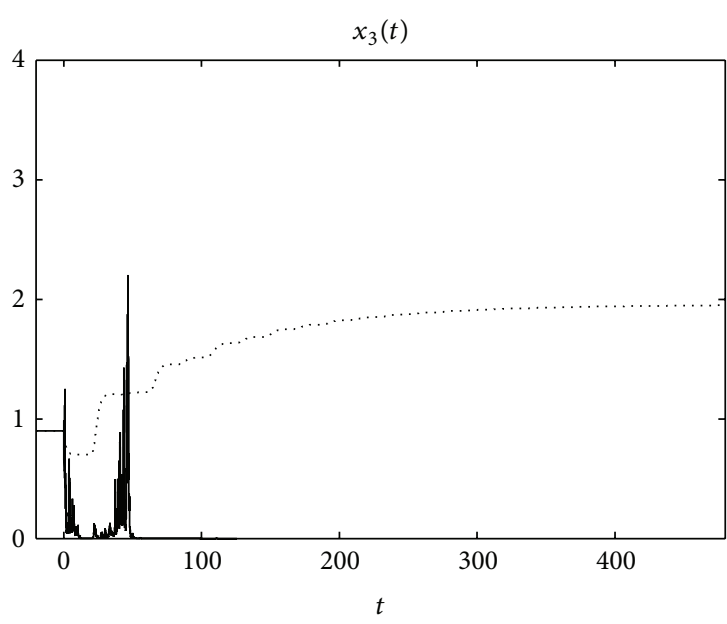

(c)

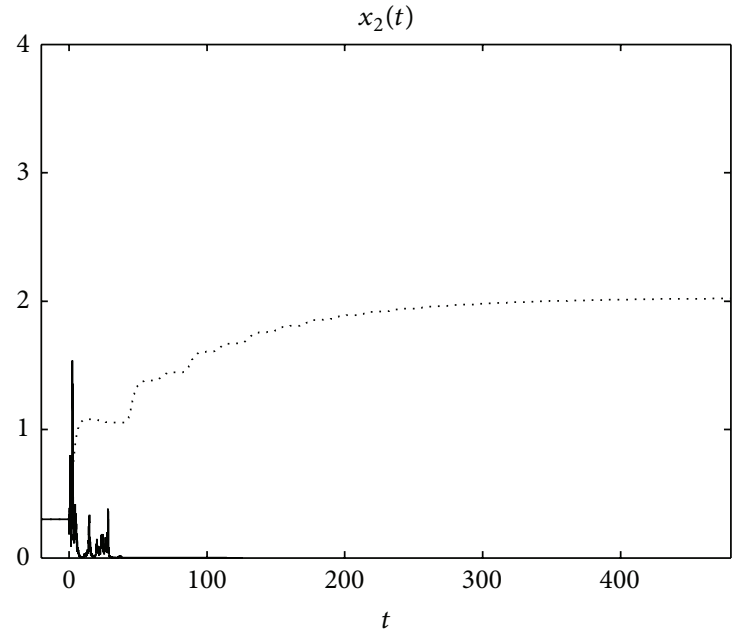

(b)

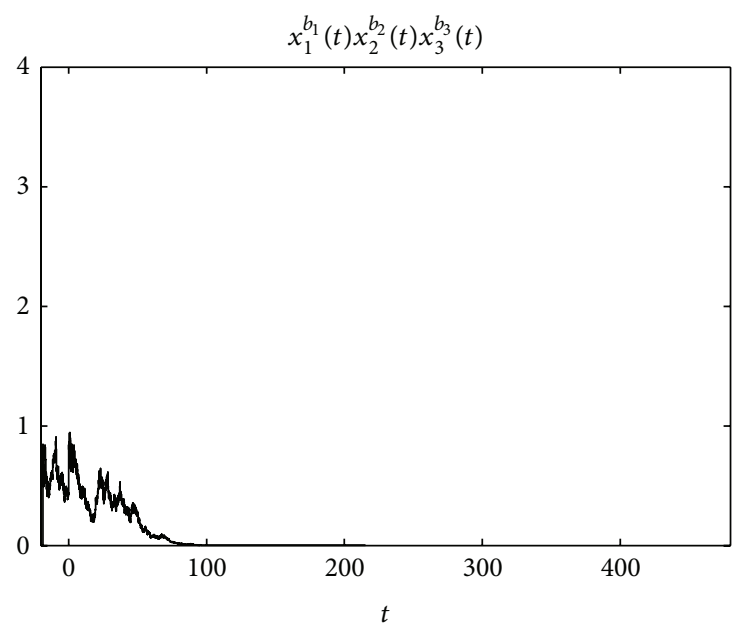

(d)

Figure 7: The solution (imaginary line) of system (8) and the solution (real line) of system (9) with $\sigma_{1}=0.04, \sigma_{2}=1.17, \sigma_{3}=1.36, \Delta t=$ 0.005 .

$$
\begin{aligned}
& -\frac{\left(a_{22}-a_{21}-a_{23}\right) c_{2}+1}{2} E \frac{1}{t} \int_{0}^{t}\left[x_{2}(s)-x_{2}^{*}\right]^{2} d s \\
& -\frac{\left(a_{33}-a_{31}-a_{32}\right) c_{3}+1}{2} E \frac{1}{t} \int_{0}^{t}\left[x_{3}(s)-x_{3}^{*}\right]^{2} d s \\
& +\frac{c_{1} x_{1}^{*} \sigma_{1}^{2}+c_{2} x_{2}^{*} \sigma_{2}^{2}+c_{3} x_{3}^{*} \sigma_{3}^{2}}{2} .
\end{aligned}
$$

Letting $t \rightarrow \infty$, therefore we have

$$
\begin{aligned}
& \limsup _{t \rightarrow \infty} \frac{1}{t} E \int_{0}^{t}\left\{\frac{\left(a_{11}-a_{12}-a_{13}\right) c_{1}+1}{2}\left[x_{1}(s)-x_{1}^{*}\right]^{2}\right. \\
& +\frac{\left(a_{22}-a_{21}-a_{23}\right) c_{2}+1}{2}\left[x_{2}(s)-x_{2}^{*}\right]^{2}
\end{aligned}
$$

$$
\left.+\frac{\left(a_{33}-a_{31}-a_{32}\right) c_{3}+1}{2}\left[x_{3}(s)-x_{3}^{*}\right]^{2}\right\} d s
$$$$
\leq \frac{\sum_{i=1}^{3} c_{i} x_{i}^{*} \sigma_{i}^{2}}{2}
$$

which is the required assertion. The proof is completed.

\section{B. Proof of Theorem 11}

Proof. It is sufficient to prove

$$
\begin{aligned}
\tilde{x}_{i}^{*} & \leq \liminf _{t \rightarrow \infty} \frac{1}{t} \int_{0}^{t} x_{i}(s) d s \\
& \leq \limsup _{t \rightarrow \infty} \frac{1}{t} \int_{0}^{t} x_{i}(s) d s \leq \tilde{x}_{i}^{*} \quad \text { a.s. } i=1,2,3 .
\end{aligned}
$$




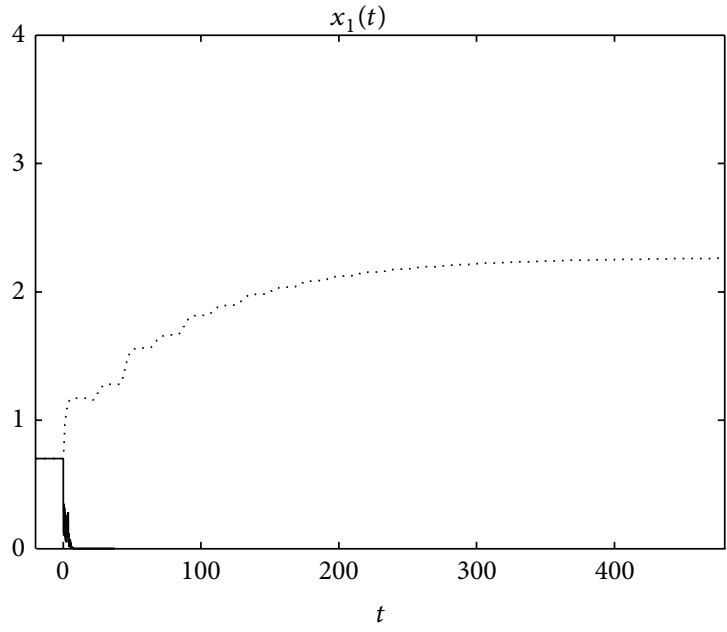

(a)

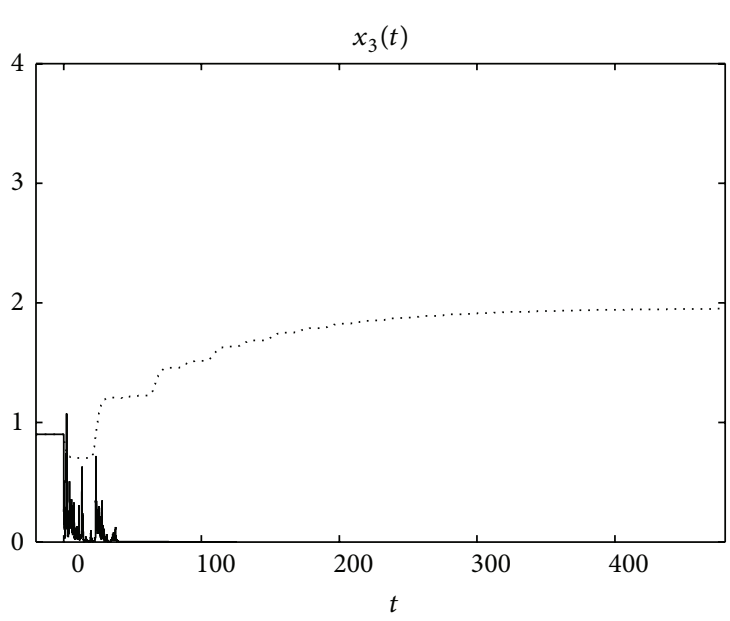

(c)

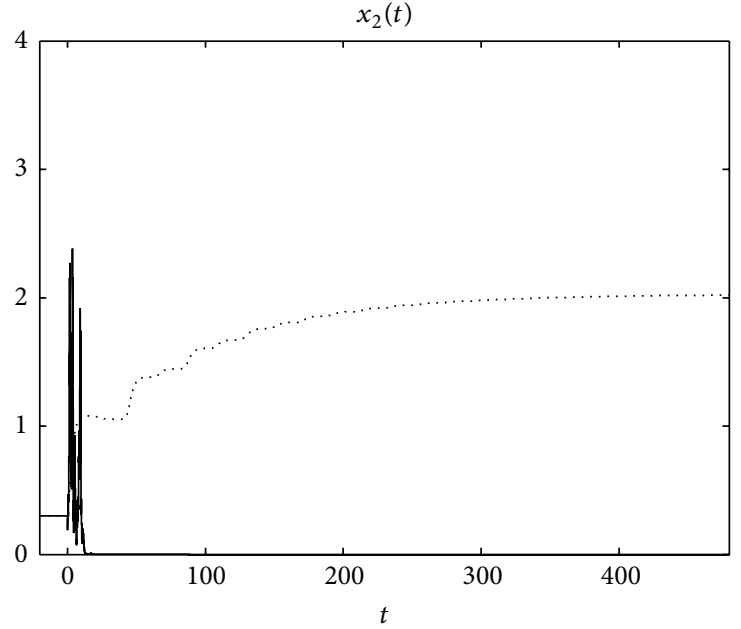

(b)

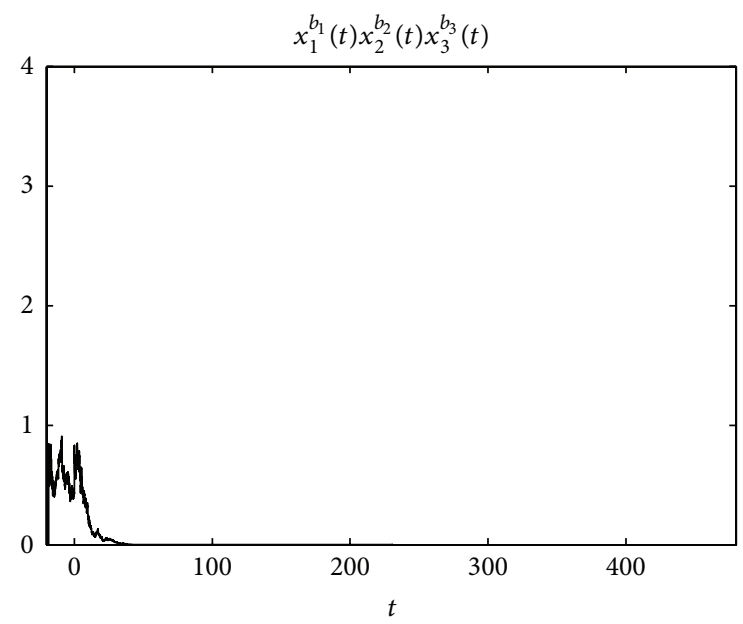

(d)

Figure 8: The solution (imaginary line) of system (8) and the solution (real line) of system (9) with $\sigma_{1}=1.25, \sigma_{2}=1.01, \sigma_{3}=1.36, \Delta t=$ 0.005 .

By Itô's formula, we have

$$
\begin{aligned}
& d \log x_{1}(t) \\
& =\left(r_{1}-\frac{\sigma_{1}^{2}}{2}-a_{11} x_{1}(t)+a_{12} x_{2}(t-\tau)+a_{13} x_{3}(t-\tau)\right) d t \\
& \quad+\sigma_{1} d B_{1}(t),
\end{aligned}
$$

$d \log x_{2}(t)$

$$
\begin{aligned}
= & \left(r_{2}-\frac{\sigma_{2}^{2}}{2}+a_{21} x_{1}(t-\tau)-a_{22} x_{2}(t)+a_{23} x_{3}(t-\tau)\right) d t \\
& +\sigma_{2} d B_{2}(t),
\end{aligned}
$$

$d \log x_{3}(t)$

$$
\begin{aligned}
= & \left(r_{3}-\frac{\sigma_{3}^{2}}{2}+a_{31} x_{1}(t-\tau)+a_{32} x_{2}(t-\tau)-a_{33} x_{3}(t)\right) d t \\
& +\sigma_{3} d B_{3}(t) .
\end{aligned}
$$

Integrating both sides of (B.2) from 0 to $t$, then we have

$$
\begin{aligned}
& \log x_{1}(t) \\
& =\log x_{1}(0)+\bar{r}_{1} t+a_{12} \int_{-\tau}^{0} \xi_{2}(s) d s+a_{13} \int_{-\tau}^{0} \xi_{3}(s) d s \\
& \quad-a_{11} \int_{0}^{t} x_{1}(s) d s+a_{12} \int_{0}^{t-\tau} x_{2}(s) d s \\
& \quad+a_{13} \int_{0}^{t-\tau} x_{3}(s) d s+\sigma_{1} B_{1}(t)
\end{aligned}
$$


$\log x_{2}(t)$

$$
\begin{aligned}
= & \log x_{2}(0)+\bar{r}_{2} t+a_{21} \int_{-\tau}^{0} \xi_{1}(s) d s+a_{23} \int_{-\tau}^{0} \xi_{3}(s) d s \\
& +a_{21} \int_{0}^{t-\tau} x_{1}(s) d s-a_{22} \int_{0}^{t} x_{2}(s) d s \\
& +a_{23} \int_{0}^{t-\tau} x_{3}(s) d s+\sigma_{2} B_{2}(t),
\end{aligned}
$$

$\log x_{3}(t)$

$$
\begin{aligned}
& =\log x_{3}(0)+\bar{r}_{3} t+a_{31} \int_{-\tau}^{0} \xi_{1}(s) d s+a_{32} \int_{-\tau}^{0} \\
& +a_{31} \int_{0}^{t-\tau} x_{1}(s) d s+a_{32} \int_{0}^{t-\tau} x_{2}(s) d s \\
& \quad-a_{33} \int_{0}^{t} x_{3}(s) d s+\sigma_{3} B_{3}(t),
\end{aligned}
$$

where $\bar{r}_{i}=r_{i}-\left(\sigma_{i}^{2} / 2\right), i=1,2,3$. From (33), we know

$$
\begin{aligned}
& \liminf _{t \rightarrow \infty} \frac{1}{t} \int_{0}^{t} x_{1}(s) d s \geq \frac{\bar{r}_{1}}{a_{11}}:=M_{1}, \\
& \liminf _{t \rightarrow \infty} \frac{1}{t} \int_{0}^{t} x_{2}(s) d s \geq \frac{\bar{r}_{2}}{a_{22}}:=N_{1}, \\
& \liminf _{t \rightarrow \infty} \frac{1}{t} \int_{0}^{t} x_{3}(s) d s \geq \frac{\bar{r}_{3}}{a_{33}}:=L_{1} .
\end{aligned}
$$

Hence, for any sufficiently small $0<\varepsilon_{1}<$ $(1 / 2) \min \left\{M_{1}, N_{1}, L_{1}\right\}$, there is a $T_{1}(\omega)>0$ such that if $t>T_{1}(\omega),(t-\tau) / t \geq 1-\varepsilon_{1},(1 / t) \int_{0}^{t} x_{1}(s) d s \geq M_{1}-\varepsilon_{1}$, $(1 / t) \int_{0}^{t} x_{2}(s) d s \geq N_{1}-\varepsilon_{1},(1 / t) \int_{0}^{t} x_{3}(s) d s \geq L_{1}-\varepsilon_{1}$. It follows from (B.3) that for $t>T_{1}(\omega)+\tau$,

$$
\begin{aligned}
\log x_{1}(t)= & \log x_{1}(0)+\bar{r}_{1} t+a_{12} \int_{-\tau}^{0} x_{2}(s) d s \\
& +a_{13} \int_{-\tau}^{0} x_{3}(s) d s-a_{11} \int_{0}^{t} x_{1}(s) d s \\
& +a_{12} \int_{0}^{t-\tau} x_{2}(s) d s+a_{13} \int_{0}^{t-\tau} x_{3}(s) d s+\sigma_{1} B_{1}(t) \\
= & \log x_{1}(0)+\bar{r}_{1} t+a_{12} \int_{-\tau}^{0} x_{2}(s) d s \\
& +a_{13} \int_{-\tau}^{0} x_{3}(s) d s-a_{11} \int_{0}^{t} x_{1}(s) d s \\
& +a_{12}(t-\tau) \frac{1}{t-\tau} \int_{0}^{t-\tau} x_{2}(s) d s
\end{aligned}
$$

$$
\begin{aligned}
& +a_{13}(t-\tau) \frac{1}{t-\tau} \int_{0}^{t-\tau} x_{3}(s) d s+\sigma_{1} B_{1}(t) \\
\geq & \log x_{1}(0)+\bar{r}_{1} t+a_{12} \int_{-\tau}^{0} x_{2}(s) d s \\
& +a_{13} \int_{-\tau}^{0} x_{3}(s) d s-a_{11} \int_{0}^{t} x_{1}(s) d s+a_{12}(t-\tau) \\
& \times\left(N_{1}-\varepsilon_{1}\right)+a_{13}(t-\tau)\left(L_{1}-\varepsilon_{1}\right)+\sigma_{1} B_{1}(t) \\
= & {\left[\bar{r}_{1}+a_{12}\left(N_{1}-\varepsilon_{1}\right)+a_{13}\left(L_{1}-\varepsilon_{1}\right)\right] t } \\
& -a_{11} \int_{0}^{t} x_{1}(s) d s+\sigma_{1} B_{1}(t)+S_{1},
\end{aligned}
$$

where

$$
\begin{aligned}
S_{1}= & \log x_{1}(0)-\left[a_{12}\left(N_{1}-\varepsilon_{1}\right)+a_{13}\left(L_{1}-\varepsilon_{1}\right)\right] \tau \\
& +a_{12} \int_{-\tau}^{0} x_{2}(s) d s+a_{13} \int_{-\tau}^{0} x_{3}(s) d s .
\end{aligned}
$$

We know

$$
\lim _{t \rightarrow \infty} \frac{\sigma_{1} B_{1}(t)+S_{1}}{t}=0 .
$$

From Lemma 10, we have

$$
\begin{aligned}
\liminf _{t \rightarrow \infty} \frac{1}{t} \int_{0}^{t} x_{1}(s) d s & \\
& \geq \frac{\bar{r}_{1}+a_{12}\left(N_{1}-\varepsilon_{1}\right)+a_{13}\left(L_{1}-\varepsilon_{1}\right)}{a_{11}}:=M_{2} .
\end{aligned}
$$

Similarly,

$$
\begin{aligned}
& \liminf _{t \rightarrow \infty} \frac{1}{t} \int_{0}^{t} x_{2}(s) d s \\
& \geq \frac{\bar{r}_{2}+a_{21}\left(M_{1}-\varepsilon_{1}\right)+a_{23}\left(L_{1}-\varepsilon_{1}\right)}{a_{22}}:=N_{2}, \\
& \liminf _{t \rightarrow \infty} \frac{1}{t} \int_{0}^{t} x_{3}(s) d s \\
& \geq \frac{\bar{r}_{3}+a_{31}\left(M_{1}-\varepsilon_{1}\right)+a_{32}\left(N_{1}-\varepsilon_{1}\right)}{a_{33}}:=L_{2} .
\end{aligned}
$$

Let $\varepsilon_{2}=(1 / 2) \min \left\{M_{2}, N_{2}, L_{2}, \varepsilon_{1}\right\}$, continuing this process, we obtain sequences $\left\{M_{n}\right\},\left\{N_{n}\right\},\left\{L_{n}\right\},\left\{\varepsilon_{n}\right\}$, where

$$
\begin{aligned}
& M_{n}=\frac{\bar{r}_{1}+a_{12}\left(N_{n-1}-\varepsilon_{n-1}\right)+a_{13}\left(L_{n-1}-\varepsilon_{n-1}\right)}{a_{11}}, \\
& N_{n}=\frac{\bar{r}_{2}+a_{21}\left(M_{n-1}-\varepsilon_{n-1}\right)+a_{23}\left(L_{n-1}-\varepsilon_{n-1}\right)}{a_{22}}, \\
& L_{n}=\frac{\bar{r}_{3}+a_{31}\left(M_{n-1}-\varepsilon_{n-1}\right)+a_{32}\left(N_{n-1}-\varepsilon_{n-1}\right)}{a_{33}}, \\
& \varepsilon_{n}=\frac{1}{2} \min \left\{M_{n}, N_{n}, L_{n}, \varepsilon_{n-1}\right\} .
\end{aligned}
$$


Sequence $\left\{M_{n}\right\},\left\{N_{n}\right\},\left\{L_{n}\right\}$ is nondecreasing and bounded; then we have

$$
\begin{aligned}
& \liminf _{t \rightarrow \infty} \frac{1}{t} \int_{0}^{t} x_{1}(s) d s \geq M_{n}, \\
& \liminf _{t \rightarrow \infty} \frac{1}{t} \int_{0}^{t} x_{2}(s) d s \geq N_{n}, \\
& \liminf _{t \rightarrow \infty} \frac{1}{t} \int_{0}^{t} x_{3}(s) d s \geq L_{n} .
\end{aligned}
$$

Let $n \rightarrow \infty$; we derive from (B.10) that

$$
\begin{array}{ll}
\lim _{n \rightarrow \infty} \varepsilon_{n}=0, & \lim _{n \rightarrow \infty} M_{n}=\tilde{x}_{1}^{*}, \\
\lim _{n \rightarrow \infty} N_{n}=\tilde{x}_{2}^{*}, & \lim _{n \rightarrow \infty} L_{n}=\tilde{x}_{3}^{*},
\end{array}
$$

where $\tilde{x}_{1}^{*}, \tilde{x}_{2}^{*}, \tilde{x}_{3}^{*}$ is the unique solution of the following equation:

$$
\begin{aligned}
& \bar{r}_{1}-a_{11} \tilde{x}_{1}^{*}+a_{12} \tilde{x}_{2}^{*}+a_{13} \tilde{x}_{3}^{*}=0, \\
& \bar{r}_{2}+a_{21} \tilde{x}_{1}^{*}-a_{22} \tilde{x}_{2}^{*}+a_{23} \tilde{x}_{3}^{*}=0, \\
& \bar{r}_{3}+a_{31} \tilde{x}_{1}^{*}+a_{32} \tilde{x}_{2}^{*}-a_{33} \tilde{x}_{3}^{*}=0 .
\end{aligned}
$$

Thus we obtain the assertion

$$
\liminf _{t \rightarrow \infty} \frac{1}{t} \int_{0}^{t} x_{i}(s) d s \geq \tilde{x}_{i}^{*} \quad i=1,2,3 \text { a.s. }
$$

Next, we will prove

$$
\limsup _{t \rightarrow \infty} \frac{1}{t} \int_{0}^{t} x_{i}(s) d s \leq \tilde{x}_{i}^{*} \quad i=1,2,3 \text { a.s. }
$$

It follows from (B.2) that

$$
\begin{gathered}
d\left[\log x_{1}(t)+a_{12} \int_{t}^{t+\tau} x_{2}(s-\tau) d s+a_{13} \int_{t}^{t+\tau} x_{3}(s-\tau) d s\right] \\
=\left[\bar{r}_{1}-a_{11} x_{1}(t)+a_{12} x_{2}(t)+a_{13} x_{3}(t)\right] d t+\sigma_{1} d B_{1}(t)
\end{gathered}
$$

Integrating both sides of (B.16) from 0 to $t$, we have

$$
\begin{aligned}
& \log x_{1}(t)+a_{12} \int_{t}^{t+\tau} x_{2}(s-\tau) d s-a_{12} \int_{0}^{\tau} x_{2}(s-\tau) d s \\
& \quad+a_{13} \int_{t}^{t+\tau} x_{3}(s-\tau) d s-a_{13} \int_{0}^{\tau} x_{3}(s-\tau) d s \\
& =\log x_{1}(0)+\bar{r}_{1} t-a_{11} \int_{0}^{t} x_{1}(s) d s+a_{12} \int_{0}^{t} x_{2}(s) d s \\
& \quad+a_{13} \int_{0}^{t} x_{3}(s) d s+\sigma_{1} B_{1}(t) .
\end{aligned}
$$

Since $x_{i}(t)>0, i=1,2,3$, we have

$$
\begin{aligned}
\log x_{1}(t) \leq & U_{1}+\bar{r}_{1} t-a_{11} \int_{0}^{t} x_{1}(s) d s \\
& +a_{12} \int_{0}^{t} x_{2}(s) d s+a_{13} \int_{0}^{t} x_{3}(s) d s+\sigma_{1} B_{1}(t)
\end{aligned}
$$

where

$$
U_{1}=a_{12} \int_{0}^{\tau} x_{2}(s-\tau) d s+a_{13} \int_{0}^{\tau} x_{3}(s-\tau) d s+\log x_{1}(0) .
$$

Similarly,

$$
\begin{aligned}
\log x_{2}(t) \leq & U_{2}+\bar{r}_{2} t-a_{22} \int_{0}^{t} x_{2}(s) d s \\
& +a_{21} \int_{0}^{t} x_{1}(s) d s+a_{23} \int_{0}^{t} x_{3}(s) d s+\sigma_{2} B_{2}(t),
\end{aligned}
$$

where

$$
\begin{gathered}
U_{2}=a_{21} \int_{0}^{\tau} x_{1}(s-\tau) d s+a_{23} \int_{0}^{\tau} x_{3}(s-\tau) d s+\log x_{2}(0) \\
\log x_{3}(t) \leq U_{3}+\bar{r}_{3} t-a_{33} \int_{0}^{t} x_{3}(s) d s+a_{31} \int_{0}^{t} x_{1}(s) d s \\
+a_{32} \int_{0}^{t} x_{2}(s) d s+\sigma_{3} B_{3}(t)
\end{gathered}
$$

where

$$
U_{3}=a_{31} \int_{0}^{\tau} x_{1}(s-\tau) d s+a_{32} \int_{0}^{\tau} x_{2}(s-\tau) d s+\log x_{3}(0) .
$$

Let $b_{11}$ be a positive constant

$$
\begin{aligned}
& b_{12}=\frac{-a_{12} a_{33}-a_{13} a_{32}}{a_{23} a_{32}-a_{33} a_{22}} b_{11}, \\
& b_{13}=\frac{-a_{23} a_{12}-a_{13} a_{22}}{a_{23} a_{32}-a_{33} a_{22}} b_{11},
\end{aligned}
$$

$$
\begin{aligned}
& m_{1} \\
& =a_{11} b_{11}-a_{21} \frac{-a_{12} a_{33}-a_{13} a_{32}}{a_{23} a_{32}-a_{33} a_{22}} b_{11}-a_{31} \frac{-a_{23} a_{12}-a_{13} a_{22}}{a_{23} a_{32}-a_{33} a_{22}} b_{11} \\
& =\left(\left(-a_{11} a_{22} a_{33}+a_{11} a_{23} a_{32}+a_{22} a_{13} a_{31}+a_{33} a_{12} a_{21}\right.\right. \\
& \left.\left.\quad+a_{12} a_{23} a_{31}+a_{21} a_{32} a_{13}\right)\left(a_{23} a_{32}-a_{33} a_{22}\right)^{-1}\right) b_{11} .
\end{aligned}
$$

From Lemma 3, we know $b_{12}>0, b_{13}>0, m_{1}>0$. Since $x_{i}(t)>0$, from (B.18)-(B.22) we have

$$
\begin{aligned}
b_{11} \log x_{1}(t)+b_{12} \log x_{2}(t)+b_{13} \log x_{3}(t) \\
=\left[b_{11} \bar{r}_{1}+b_{12} \bar{r}_{2}+b_{13} \bar{r}_{3}\right] t-m_{1} \int_{0}^{t} x_{1}(s) d s \\
+\sum_{i=1}^{3} b_{1 i} \sigma_{i} B_{i}(t)+\sum_{i=1}^{3} b_{1 i} U_{i} .
\end{aligned}
$$


From (33), we know

$$
\liminf _{t \rightarrow \infty} \frac{\log x_{i}(t)}{t} \geq 0 \quad i=1,2,3,
$$

which implies

$$
\lim _{t \rightarrow \infty} \frac{b_{11} \log x_{1}(t)+b_{12} \log x_{2}(t)+b_{13} \log x_{3}(t)}{t} \geq 0 .
$$

From

$$
\lim _{t \rightarrow \infty} \frac{\sum_{i=1}^{3} b_{1 i} \sigma_{i} B_{i}(t)+\sum_{i=1}^{3} b_{1 i} U_{i}}{t}=0,
$$

we have

$$
\limsup _{t \rightarrow \infty} \frac{1}{t} \int_{0}^{t} x_{1}(s) d s \leq \frac{b_{11} \bar{r}_{1}+b_{12} \bar{r}_{2}+b_{13} \bar{r}_{3}}{m_{1}}=\tilde{x}_{1}^{*} .
$$

Similarly,

$$
\begin{aligned}
& \limsup _{t \rightarrow \infty} \frac{1}{t} \int_{0}^{t} x_{2}(s) d s \leq \tilde{x}_{2}^{*}, \\
& \limsup _{t \rightarrow \infty} \frac{1}{t} \int_{0}^{t} x_{3}(s) d s \leq \tilde{x}_{3}^{*} .
\end{aligned}
$$

Therefore, $\lim \sup _{t \rightarrow \infty}(1 / t) \int_{0}^{t} x(s) d s \leq \tilde{x}^{*}$. The proof is completed.

\section{Conflict of Interests}

The authors declare that there is no conflict of interests regarding the publication of this paper.

\section{Acknowledgments}

The work was supported by the NSFC of China (no. 11371085) and the Ph.D. Programs Foundation of Ministry of China (no. 200918).

\section{References}

[1] B. S. Goh, "Stability in models of mutualism," The American Naturalist, vol. 113, no. 2, pp. 261-275, 1979.

[2] C. Zen, C. g, H. Qinglin, Y. Tao, W. Hua, and J. Zhenglin, "Noise- and delay-induced regime shifts in an ecological system of vegetation," Journal of Statistical Mechanics: Theory and Experiment, vol. 2013, Article ID P10017, 2013.

[3] C. Zeng and H. Wang, "Noise-and delay-induced phase transitions of the dimerCmonomer surface reaction model," Chemical Physics, vol. 402, pp. 1-5.

[4] X.-Z. He and K. Gopalsamy, "Persistence, attractivity, and delay in facultative mutualism," Journal of Mathematical Analysis and Applications, vol. 215, no. 1, pp. 154-173, 1997.

[5] H. Wu, Y. Xia, and M. Lin, "Existence of positive periodic solution of mutualism system with several delays," Chaos, Solitons \& Fractals, vol. 36, no. 2, pp. 487-493, 2008.
[6] Y. Xia, "Existence of positive periodic solutions of mutualism systems with several delays," Advances in Dynamical Systems and Applications, vol. 1, no. 2, pp. 209-217, 2006.

[7] F. Yang and D. Q. Jiang, "Global attractivity of the positive periodic solution of a facultative mutualism system with several delays," Acta Mathematica Scientia A, vol. 22, no. 4, pp. 518-524, 2002.

[8] A. Bahar and X. Mao, "Stochastic delay Lotka-Volterra model," Journal of Mathematical Analysis and Applications, vol. 292, no. 2, pp. 364-380, 2004.

[9] A. Bahar and X. Mao, "Stochastic delay population dynamics," International Journal of Pure and Applied Mathematics, vol. 11, no. 4, pp. 377-400, 2004.

[10] T. C. Gard, "Persistence in stochastic food web models," Bulletin of Mathematical Biology, vol. 46, no. 3, pp. 357-370, 1984.

[11] T. C. Gard, "Stability for multispecies population models in random environments," Nonlinear Analysis: Theory, Methods of Applications, vol. 10, no. 12, pp. 1411-1419, 1986.

[12] T. C. Gard, Introduction to Stochastic Differential Equations, vol. 114, Marcel Dekker, New York, NY, USA, 1988.

[13] C. Ji, D. Jiang, and N. Shi, "Analysis of a predator-prey model with modified Leslie-Gower and Holling-type II schemes with stochastic perturbation," Journal of Mathematical Analysis and Applications, vol. 359, no. 2, pp. 482-498, 2009.

[14] C. Ji, D. Jiang, H. Liu, and Q. Yang, "Existence, uniqueness and ergodicity of positive solution of mutualism system with stochastic perturbation," Mathematical Problems in Engineering, vol. 2010, Article ID 684926, 18 pages, 2010.

[15] C. Ji and D. Jiang, "Dynamics of a stochastic density dependent predator-prey system with Beddington-DeAngelis functional response," Journal of Mathematical Analysis and Applications, vol. 381, no. 1, pp. 441-453, 2011.

[16] C. Ji and D. Jiang, "Ergodicity of positive solution of mutualism systemwith stochastic perturbation," Journal of Mathematical Analysis and Applications. In press.

[17] D. Jiang and N. Shi, "A note on nonautonomous logistic equation with random perturbation," Journal of Mathematical Analysis and Applications, vol. 303, no. 1, pp. 164-172, 2005.

[18] D. Jiang, N. Shi, and X. Li, "Global stability and stochastic permanence of a non-autonomous logistic equation with random perturbation," Journal of Mathematical Analysis and Applications, vol. 340, no. 1, pp. 588-597, 2008.

[19] D. Jiang, C. Ji, N. Shi, and J. Yu, "The long time behavior of DI SIR epidemic model with stochastic perturbation," Journal of Mathematical Analysis and Applications, vol. 372, no. 1, pp. 162-180, 2010.

[20] R. Z. Khasminskii and F. C. Klebaner, "Long term behavior of solutions of the Lotka-Volterra system under small random perturbations," The Annals of Applied Probability, vol. 11, no. 3, pp. 952-963, 2001.

[21] X. Li, D. Jiang, and X. Mao, "Population dynamical behavior of Lotka-Volterra system under regime switching," Journal of Computational and Applied Mathematics, vol. 232, no. 2, pp. 427-448, 2009.

[22] X. Li and X. Mao, "Population dynamical behavior of nonautonomous Lotka-Volterra competitive system with random perturbation," Discrete and Continuous Dynamical Systems. Series A, vol. 24, no. 2, pp. 523-545, 2009.

[23] X. Mao, Stochastic Differential Equations and Applications, Horwood, Chichester, UK, 1997. 
[24] X. Mao, G. Marion, and E. Renshaw, "Environmental Brownian noise suppresses explosions in population dynamics," Stochastic Processes and their Applications, vol. 97, no. 1, pp. 95-110, 2002.

[25] X. Mao, S. Sabanis, and E. Renshaw, "Asymptotic behaviour of the stochastic Lotka-Volterra model," Journal of Mathematical Analysis and Applications, vol. 287, no. 1, pp. 141-156, 2003.

[26] X. Mao, C. Yuan, and J. Zou, "Stochastic differential delay equations of population dynamics," Journal of Mathematical Analysis and Applications, vol. 304, no. 1, pp. 296-320, 2005.

[27] R. May, Stability and Complexity in Model Ecosystems, Princeton University, Princeton, NJ, USA, 2001.

[28] L. Arnold, W. Horsthemke, and J. W. Stucki, "The influence of external real and white noise on the Lotka-Volterra model," Biometrical Journal, vol. 21, no. 5, pp. 451-471, 1979.

[29] P. Xia and D. Jiang, "Persistence and non-persistence of a non-autonomous stochastic mutualism system," Abstract and Applied Analysis, vol. 2013, Article ID 256249, 13 pages, 2013.

[30] D. J. Higham, "An algorithmic introduction to numerical simulation of stochastic differential equations," SIAM Review, vol. 43, no. 3, pp. 525-546, 2001. 


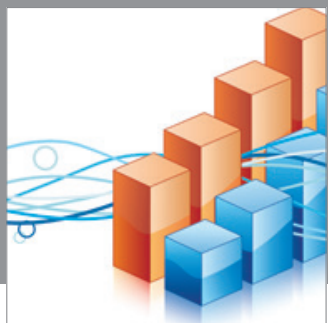

Advances in

Operations Research

mansans

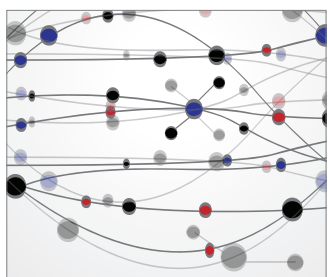

The Scientific World Journal
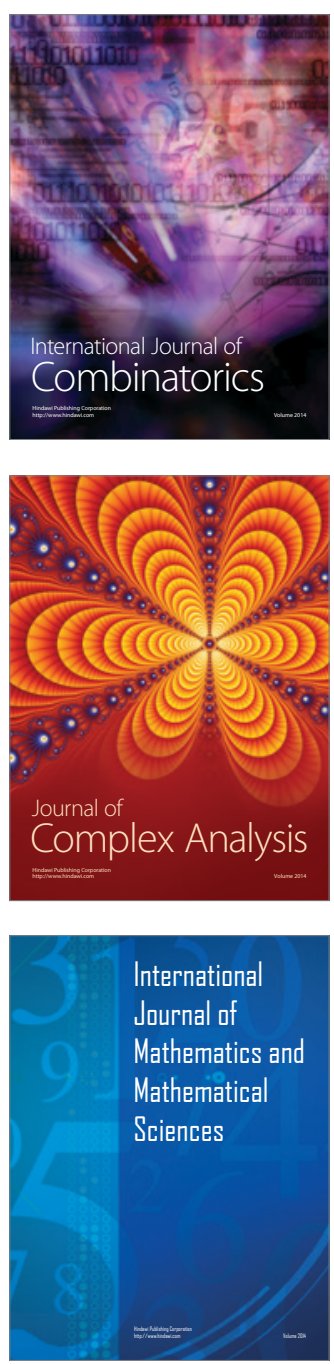
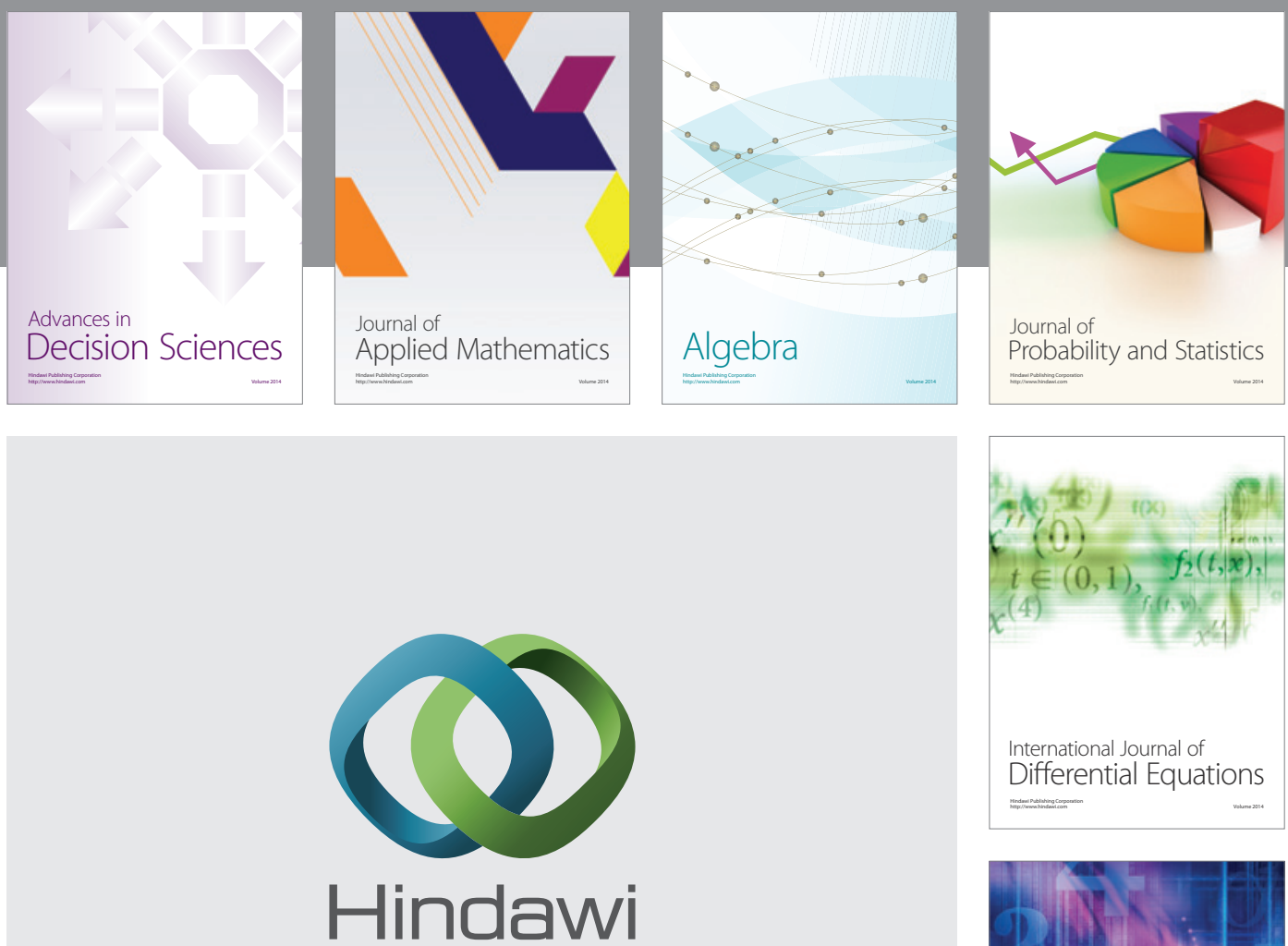

Submit your manuscripts at http://www.hindawi.com
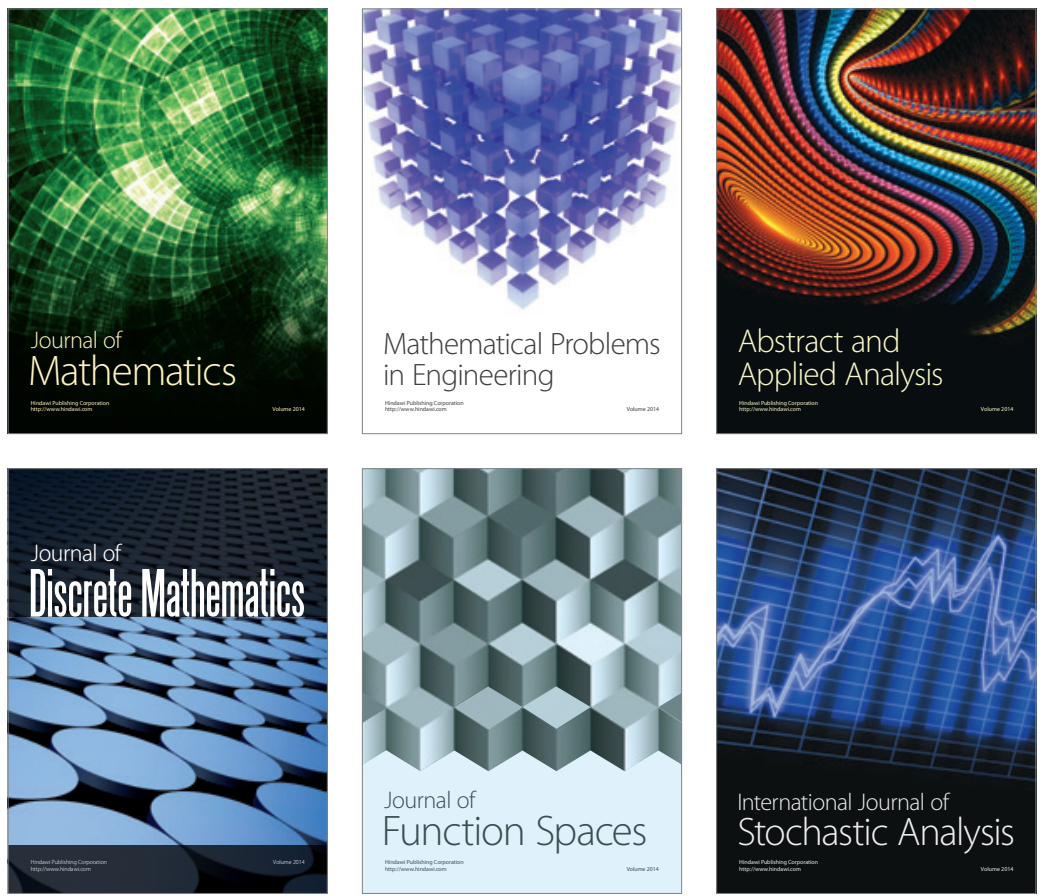

Journal of

Function Spaces

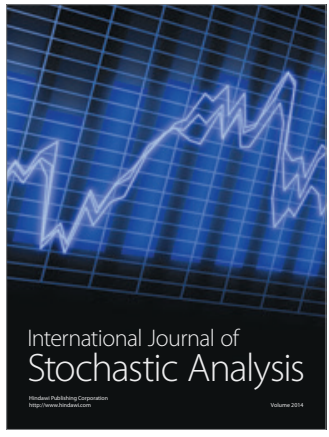

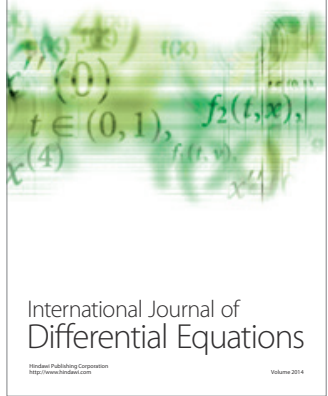
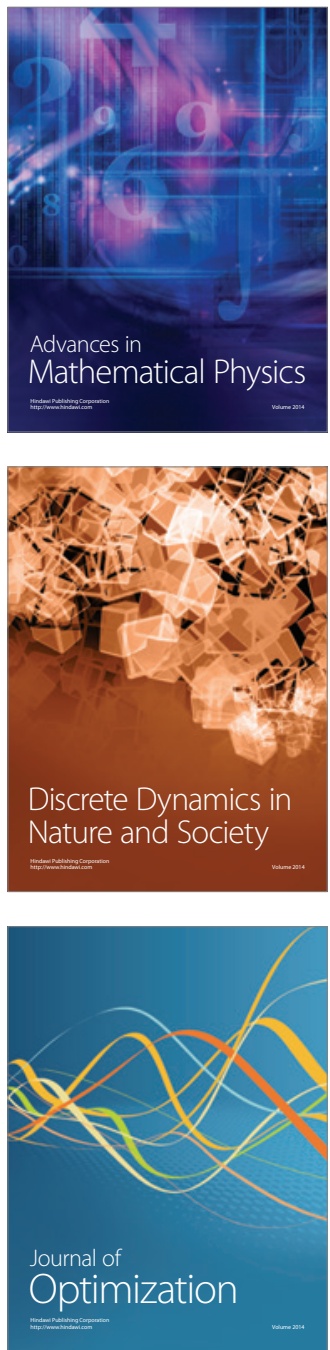